OPEN ACCESS

Edited by:

Eleanor Riley,

London School of Hygiene \& Tropical

Medicine, UK

Reviewed by:

Salim labal Khakoo,

University of Southampton, UK

Marcus Altfeld,

Ragon Institute of MGH, MIT and

Harvard, USA

*Correspondence:

Eric O. Long

elong@nih.gov;

Rosemary J. Boyton

r.boyton@imperial.ac.uk

${ }^{+}$Co-senior authors.

Specialty section: This article was submitted to NK and Innate Lymphoid Cell Biology,

a section of the journal

Frontiers in Immunology

Received: 03 January 2017 Accepted: 09 February 2017

Published: 14 March 2017

Citation:

Sim MJW, Malaker SA, Khan A

Stowell JM, Shabanowitz J,

Peterson ME, Rajagopalan S, Hunt DF, Altmann DM, Long EO and

Boyton RJ (2017) Canonical and Cross-reactive Binding of NK Cell

Inhibitory Receptors to HLA-C

Allotypes Is Dictated by Peptides

Bound to HLA-C.

Front. Immunol. 8:193.

doi: 10.3389/fimmu.2017.00193

\section{Canonical and Cross-reactive Binding of NK Cell Inhibitory Receptors to HLA-C Allotypes Is Dictated by Peptides Bound to HLA-C}

\author{
Malcolm J. W. Sim ${ }^{1,2}$, Stacy A. Malaker, ${ }^{3,4}$, Ayesha Khan', Janet M. Stowell', \\ Jeffrey Shabanowitz ${ }^{3}$, Mary E. Peterson', Sumati Rajagopalan', Donald F. Hunt ${ }^{3,5}$, \\ Daniel M. Altmann ${ }^{2}$, Eric O. Long ${ }^{\text {*t }}$ and Rosemary J. Boyton ${ }^{2 *+}$
}

\begin{abstract}
'Laboratory of Immunogenetics, National Institute of Allergy and Infectious Diseases, NIH, Rockville, MD, USA, ${ }^{2}$ Lung Immunology Group, Department of Medicine, Imperial College London, London, UK, ${ }^{3}$ Department of Chemistry, University of Virginia, Charlottesville, VA, USA, ${ }^{4}$ Department of Chemistry, Stanford University, Stanford, CA, USA, ${ }^{5}$ Department of Pathology, University of Virginia, Charlottesville, VA, USA
\end{abstract}

Background: Human natural killer (NK) cell activity is regulated by a family of killer cell immunoglobulin-like receptors (KIRs) that bind human leukocyte antigen (HLA) class I. Combinations of KIR and HLA genotypes are associated with disease, including susceptibility to viral infection and disorders of pregnancy. KIR2DL1 binds HLA-C alleles of group C2 (Lys $\left.{ }^{80}\right)$. KIR2DL2 and KIR2DL3 bind HLA-C alleles of group C1 (Asn ${ }^{80}$ ). However, this model cannot explain HLA-C allelic effects in disease or the impact of HLA-bound peptides. The goal of this study was to determine the extent to which the endogenous HLA-C peptide repertoire can influence the specific binding of inhibitory KIR to HLA-C allotypes.

Results: The impact of HLA-C bound peptide on inhibitory KIR binding was investigated taking advantage of the fact that HLA-C*05:01 (HLA-C group 2, C2) and HLA-C*08:02 (HLA-C group 1, C1) have identical sequences apart from the key KIR specificity determining epitope at residues 77 and 80. Endogenous peptides were eluted from HLA$\mathrm{C}^{\star}$ 05:01 and used to test the peptide dependence of KIR2DL1 and KIR2DL2/3 binding to HLA-C*05:01 and HLA-C*08:02 and subsequent impact on NK cell function. Specific binding of KIR2DL1 to the C2 allotype occurred with the majority of peptides tested. In contrast, KIR2DL2/3 binding to the C1 allotype occurred with only a subset of peptides. Cross-reactive binding of KIR2DL2/3 with the C2 allotype was restricted to even fewer peptides. Unexpectedly, two peptides promoted binding of the C2 allotype-specific

\footnotetext{
Abbreviations: CD3, cluster of differentiation 3; CHAPS, 3-[(3-cholamidopropyl) dimethyl ammonio]-1-propanesulfonate; CMV, cytomegalovirus; EBV, Epstein-Barr virus; EDTA, ethylenediaminetetraacetic acid; FACS, fluorescence-activated cell sorting; GFP, green fluorescent protein; HCV, hepatitis C virus; HIV, human immunodeficiency virus; HLA, human leukocyte antigen; KIR, killer cell immunoglobulin-like receptor; MFI, mean fluorescence intensity; NK, natural killer; PBMC, peripheral blood mononuclear cell; PBS, phosphate-buffered saline; SP, single positive; TAP, transporter associated with antigen processing; VSV, vesicular stomatitis virus.
} 
KIR2DL1 to the C1 allotype. We showed that presentation of endogenous peptides or HIV Gag peptides by HLA-C can promote KIR cross-reactive binding.

Conclusion: KIR2DL2/3 binding to $\mathrm{C} 1$ is more peptide selective than that of KIR2DL1 binding to $\mathrm{C} 2$, providing an explanation for KIR2DL3-C1 interactions appearing weaker than KIR2DL1-C2. In addition, cross-reactive binding of KIR is characterized by even higher peptide selectivity. We demonstrate a hierarchy of functional peptide selectivity of KIR-HLA-C interactions with relevance to NK cell biology and human disease associations. This selective peptide sequence-driven binding of KIR provides a potential mechanism for pathogen as well as self-peptide to modulate NK cell activation through altering levels of inhibition.

Keywords: innate immunity, immunogenetics, natural killer cell, killer cell Ig-like receptors, human leukocyte antigen

\section{INTRODUCTION}

Natural killer (NK) cells are innate lymphocytes with important roles in immune surveillance of cancer and viral infection (1). NK cell activation is regulated by an array of activating and inhibitory receptors (2). Inhibitory receptors include CD94-NKG2A that binds human leukocyte antigen (HLA)-E and the killer cell immunoglobulin-like receptors (KIRs) that bind HLA-A, -B, and -C molecules (3). The specificity of inhibitory KIR for different HLA-C allotypes is defined by a dimorphism of a pair of amino acids at positions 77 and 80 of HLA-C, whereby KIR2DL1 binds group C2 allotypes $\left(\mathrm{Asn}^{77} \mathrm{Lys}^{80}\right)$ and KIR2DL2 and KIR2DL3 bind group $\mathrm{C} 1$ allotypes $\left(\mathrm{Ser}^{77} \mathrm{Asn}^{80}\right.$ ) (Figure 1A). Exchanging amino acids 77 and 80 from a $\mathrm{C} 1$ to a $\mathrm{C} 2$ allotype, and vice versa, revealed that position 80 was the key determinant of KIR specificity for C1 or C2 allotypes (4). A reciprocal dimorphism exists on the HLA-C-specific KIR at position 44, as KIR2DL2 and KIR2DL3 $\left(\right.$ Lys $^{44}$ ) can be converted into $\mathrm{C} 2$-binding receptors by mutation to $\mathrm{Met}^{44}$, the residue found in KIR2DL1, and vice versa (5). Genetic association studies have highlighted the importance of these interactions, linking combinations of KIR and HLA-C genes in the context of this C1-C2 model (Figure 1A), with multiple disease processes including susceptibility to infectious, autoimmune and inflammatory disease, cancer, and disorders of pregnancy (3, 6-15). Examples include protection against chronic hepatitis C virus $(\mathrm{HCV})$ infection in KIR2DL3 and HLA-C1 homozygotes and increased risk of pre-eclampsia and other pregnancy-related disorders when the fetus carries HLA-C2 (9-11).

KIR2DL3 with HLA-C1 is considered a weaker interaction than KIR2DL1 with HLA-C2, allowing disease associations to be explained through the "strength of inhibition" hypothesis, with weaker inhibitory receptor interactions leading to more NK cell activation and clearance of viral infections such as $\operatorname{HCV~}(3,6,7$, 12-15). Understanding the basis for specificity in KIR binding to HLA-C allotypes is also relevant to hematopoietic stem cell transplantation for the treatment of certain leukemias, as the clinical outcome is improved when donor KIR and recipient HLA-C genes are mismatched according to the $\mathrm{C} 1-\mathrm{C} 2$ model for KIR specificity (16-18).
Killer cell Ig-like receptors interactions with HLA-C encompass a role of bound peptide, in that certain peptide sequences are incompatible with KIR binding (19-21). The significance of HLA-C bound peptides in KIR binding for the control of NK cell immune responses has been highlighted by recent examples of HIV escape mutants that result in increased KIR binding due to single amino acid changes in particular viral epitopes $(22,23)$. The importance of side chains at positions 7 and 8 of 9 amino acid long peptides (9mers) was shown using amino acid-substituted peptide variants $(19,21,24,25)$. A study of 60 combinations of amino acid side chains at peptide positions 7 and 8 demonstrated that most combinations reduced KIR2DL2 and KIR2DL3 binding to HLA- $\mathrm{C}^{\star} 01: 02$ (C1) compared to the parent peptide eluted from HLA-C (19). To date there is no established set of rules to determine the basis for peptide selectivity of KIR for binding HLA-C, although negatively charged residues at positions 7 and 8 are poorly tolerated by $\operatorname{KIR}(19,21)$.

Along with canonical binding to C1, KIR2DL2 and KIR2DL3 display cross-reactive binding to $\mathrm{C} 2$ allotypes (26-28). In contrast, KIR2DL1 is highly specific for C2 allotypes, and no functional KIR2DL1 cross-reactivity with $\mathrm{C} 1$ allotypes has been reported (27-29). To determine the extent to which the endogenous HLA-C peptide repertoire can influence the specific binding of inhibitory KIR to HLA-C allotypes, naturally processed peptides were eluted from HLA-C ${ }^{\star} 05: 01$ and sequenced. HLA-C ${ }^{\star} 05: 01$, a classical C2 allotype with a Lys at position 80, has shown particularly strong cross-reactivity with KIR2DL2 and KIR2DL3, despite lacking the group C1 Asn at position $80(26,27)$. Taking advantage of the fact that HLA-C ${ }^{\star} 05: 01$ (HLA-C group 2, C2) and HLA-C ${ }^{\star} 08: 02$ (HLA-C group 1, C1) have identical sequences apart from the key KIR specificity determining epitope residues $77-80$, we were able to use the same panel of peptides eluted from HLA-C*05:01 to study the impact of HLA-C bound peptide on inhibitory KIR binding in the following interactions: canonical KIR2DL1-C2 and KIR2DL2/3-C1 and cross-reactive KIR2DL2/3-C2 and KIR2DL1-C1.

We show that the majority of peptides tested facilitated the canonical KIR2DL1-HLA-C ${ }^{\star}$ 05:01 (C2) interaction, whereas a more constrained set of peptides allowed the canonical 


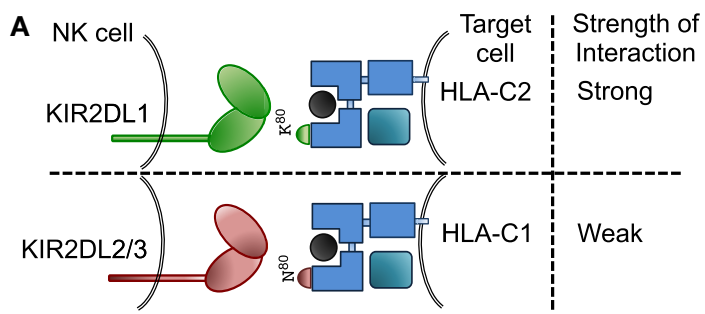

B

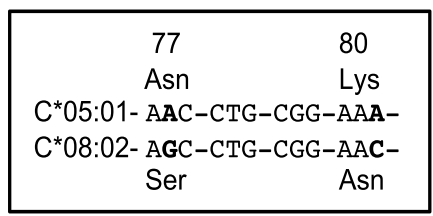

C

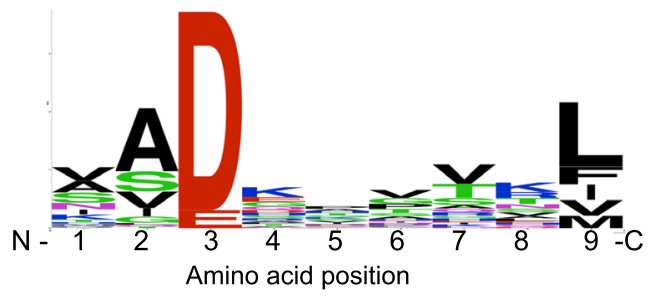

D

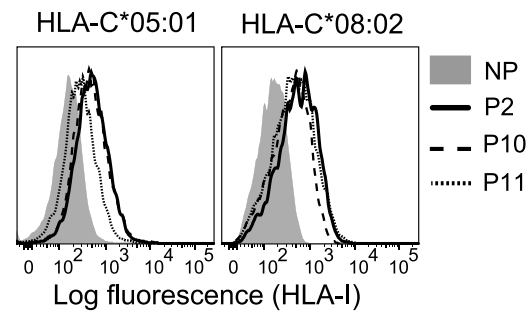

E

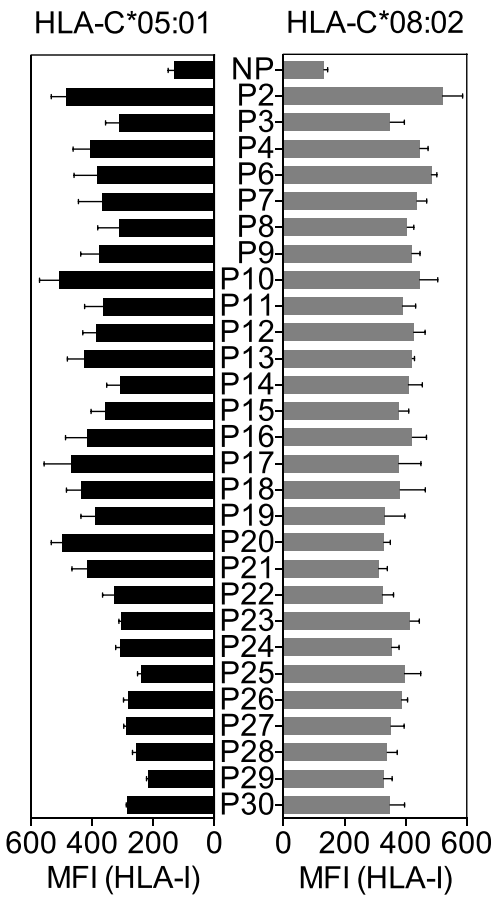

FIGURE 1 | Continued

\section{FIGURE 1 | Continued}

Human leukocyte antigen (HLA)-C*05:01 (group C2) and HLA-C*08:02 (group C1) are almost identical in sequence and HLA-C*05:01-eluted endogenous peptides bind HLA-C*05:01 and HLA-C*08:02. (A) Schematic showing how the specificity of inhibitory KIR for different HLA-C allotypes is defined by an amino acid dimorphism at positions 77 and 80 of HLA-C, where KIR2DL1 binds group C2 allotypes $\left(\right.$ Asn $^{77}$ Lys $^{80}$ ) and KIR2DL2 and KIR2DL3 bind group C1 allotypes $\left(\operatorname{Ser}^{77} A s n^{80}\right)$. (B) Nucleotide sequence alignment of amino acid positions 77-80 of HLA-C*05:01 and HLA-C*08:02 . Bold indicates nucleotide differences. (C) The motif for HLA-C*05:01 9mer peptides. (D) HLA-I expression on 221-C*05:01-ICP47 (left) and RMAS-C $\mathrm{C}^{*} 08: 02$ (right) cells after overnight incubation at $26^{\circ} \mathrm{C}$ with $100 \mu \mathrm{M}$ HLA-C ${ }^{\star} 05: 01$ peptides P2, P10, and P11 and no peptide (NP). (E) HLA-I expression on 221-C*05:01-ICP47 (left) and RMA-S-C*08:02 (right) cells after overnight incubation at $26^{\circ} \mathrm{C}$ with $100 \mu \mathrm{M}$ of 1 of $28 \mathrm{HLA}-\mathrm{C}^{*}$ 05:01 peptides and NP. Mean MFI and SEM of three independent experiments are shown.

KIR2DL2/3-HLA-C ${ }^{\star}$ 08:02 (C1) interaction, indicating that the KIR2DL2/3-C1 interaction was more peptide selective than the KIR2DL1-C2 interaction. KIR2DL2 and KIR2DL3 cross-reactive binding to HLA-C ${ }^{\star}$ 05:01 (C2) was even more peptide selective, while the KIR2DL1-HLA-C ${ }^{\star} 08: 02$ (C1) interaction was highly peptide selective, occurring with just two peptides. Our results show that peptide sequence plays a significant role in KIR binding and NK cell function. This could be exploited by pathogens. It also suggests that a greater dependence on peptide sequence by KIR2DL2/3 may underlie functional differences between KIR2DL1 and KIR2DL2/3.

\section{RESULTS}

\section{KIR2DL2 and KIR2DL3 Binding to HLA-C*08:02 (C1) Is More Peptide Selective Than KIR2DL1 Binding to HLA-C*05:01 (C2)}

To study the contribution of HLA-C bound peptides to KIR binding and specificity, we investigated the impact of KIR binding to HLA-C presenting identical peptides in the context of a $\mathrm{C} 1$ and a $\mathrm{C} 2$ allotype. HLA- $\mathrm{C}^{\star}$ 05:01 (C2) is almost identical to HLA-C*08:02 (C1), differing only at the positions (77 and 80) that define the C1/C2 allotypes (Figure 1B; Additional File S1A in Supplementary Material). Peptides naturally bound to HLA$C^{\star}$ 05:01 were isolated from 721.221- $C^{\star} 05: 01 \quad\left(221-C^{\star} 05: 01\right)$ cells and analyzed by electrospray mass spectrometry. We identified 72 peptides of which 46 were 9mers with different relative abundance values (Additional File S2 in Supplementary Material). The motif for HLA-C ${ }^{\star}$ 05:01 bound 9mer peptides showed an acidic residue at position 3 (Asp or Glu) and a predominantly hydrophobic anchor at position 9 (Figure 1C). The frequency of amino acids at each position in 9mers showed diversity of residues at most peptide positions, with positions 3 , 2, and 9 showing greater preference for particular amino acids (Figure 1C). All peptides contained an acidic residue (Asp or Glu) at position 3. Position 2 showed a preference for small residues (for example, Ala). The C-terminal anchor at position 9 was most commonly Leu, with Phe, Ile, Val, and 
Met also present. Our motif for peptides eluted and sequenced from HLA-C ${ }^{\star}$ 05:01 was similar to a motif for $\mathrm{HLA} \mathrm{C}^{\star}$ 05:01 determined using combinatorial peptide libraries and binding data (30). As expected, a very similar peptide motif had been determined for HLA-C ${ }^{\star}$ 08:02 (30).

A TAP-deficient HLA-C ${ }^{\star} 05: 01^{+}$cell line was made by expression of the herpes simplex virus-derived TAP inhibitor ICP47 (31) in 221-C*05:01 cells (221-C*05:01-ICP47; Additional File S1B in Supplementary Material). Of the 469 mers identified by mass spectrometry, we synthesized the 28 9mer HLA-C*05:01 peptides that included all combinations of amino acids found at positions 7 and 8 (Table 1). The peptide side chains at positions 7 and 8 have the greatest impact on $\operatorname{KIR}$ binding $(19,21$, $25,32)$. Each of these peptides stabilized HLA-C expression on 221-C*05:01-ICP47 cells after overnight incubation at $26^{\circ} \mathrm{C}$, as well as HLA-C ${ }^{\star} 08: 02$ expression on TAP-deficient RMA-S-C ${ }^{\star} 08: 02$ cells (Figures 1D,E) (21). We used HLA-Ctransfected cell lines with two different mechanisms of TAP impairment (ICP47 or genetic TAP deficiency). There was a significant positive correlation between stabilization of HLA-C expression on both cell lines and a similar level of expression in the absence of peptide (Figures 1D,E; Additional File S1C in Supplementary Material). There were a few exceptions, for example, peptide 20. However, as most peptides stabilized HLA-C expression on both cell lines to similar extent, we conclude that amino acids 77 and 80 on the otherwise identical HLA-C ${ }^{\star}$ 05:01 and HLA-C*08:02 do not have a strong influence on peptide loading of TAP-deficient cells. This provided us with the opportunity to compare the binding of KIR2DL1 to a C2 allotype and KIR2DL2 and KIR2DL3 binding to a C1 allotype, using the identical peptide panel.

Soluble KIR-Ig fusion proteins (KIR-Fc) were used to examine KIR2DL1 binding to HLA-C ${ }^{\star}$ 05:01 and KIR2DL2 and KIR2DL3 binding to HLA-C $\mathrm{C}^{\star}$ 08:02 on peptide-loaded TAP-deficient cells (Figures 2A,B). Most peptides, 24 of 28, promoted binding of KIR2DL1-FC to HLA-C ${ }^{\star} 05: 01$ (C2) (Figure 2B). In contrast, KIR2DL2 and KIR2DL3 binding to HLA-C ${ }^{\star} 08: 02$ (C1) occurred with only 13 and 11 of 28 peptides, respectively (Figure $2 B$ ). This finding remained the same when MFI results were normalized to HLA-I stabilization (KIF-Fc MFI/HLA-I MFI) by each peptide (Additional File S4 in Supplementary Material).

Thus, KIR2DL2 and KIR2DL3 showed greater selectivity for peptides than KIR2DL1 (13/28 and 11/28 compared to 24/28; $p<0.002$, Chi-square test). Acidic side chains (Asp or Glu) at position 7 or 8 were present in three of the four peptides that did not promote KIR2DL1 binding, in line with previous studies $(19,21)$. These three peptides were also not able to promote KIR2DL2 and KIR2DL3 binding to HLA-C ${ }^{\star} 08: 02$. Among the peptides that did not confer binding of KIR2DL2 and KIR2DL3, eight shared a positive charge at position 8 (Lys, Arg, or His), suggesting these amino acids are poorly tolerated by KIR2DL2 and KIR2DL3. Among the 11 peptides that were good for KIR2DL2 and KIR2DL3 binding, 7 had Ser or Thr at position 8 and the largest residue found at position 8 was Leu, suggesting a preference for small amino acids. These data showed that KIR2DL2 and KIR2DL3 are more stringent than KIR2DL1 in selection of peptide sequence for binding to HLA-C. The greater selectivity of KIR2DL2 and KIR2DL3 for peptide sequences seems to

TABLE 1 | Peptide sequence of 28 human leukocyte antigen-C*05:01 9mer peptides studied and their relative abundance at peptide elution.

\begin{tabular}{|c|c|c|c|}
\hline Peptide & Sequence & Protein of origin & Relative peptide abundance \\
\hline P2 & IIDKSGSTV & AP-3 complex subunit mu-1 & ++ \\
\hline P3 & VGDKPVSNF & Protein unc-119 homolog B & + \\
\hline P4 & AVDGSGTKF & Ribosome biogenesis protein WDR12 & + \\
\hline P6 & IVDRGSTNL & Alpha-adducin & + \\
\hline P7 & YVDEHGTRL & Proteasome subunit beta type- 8 & ++ \\
\hline P8 & GSDPRVTQL & RILP-like protein 2 & ++++ \\
\hline P9 & IVDRPVTLV & NADH dehydrogenase [ubiquinone] 1 beta subcomplex subunit 10 & +++ \\
\hline P10 & IVDKSGRTL & Methionine synthase & ++ \\
\hline P11 & AGDDAPRAV & $\beta$-Actin or POTE ankyrin domain family member $F$ & +++ \\
\hline P12 & VSDQANHVL & Kinesin-like protein KIF21A & ++ \\
\hline P13 & ASDHAPHTL & CAD protein & + \\
\hline P14 & VGDPHTVTV & Bromodomain-containing protein 8 & + \\
\hline P15 & KSDERPVHI & E3 ubiquitin-protein ligase TRIM33 & + \\
\hline P16 & ASDDGTVRI & WD repeat-containing protein 26 & ++ \\
\hline P17 & SIDKTGENF & $40 \mathrm{~S}$ ribosomal protein $\mathrm{S} 4, \mathrm{X}$ isoform $\mathrm{X}$ isoform & + \\
\hline P18 & TSDDVAKEF & Protein unc-13 homolog $\mathrm{C}$ & +++ \\
\hline P19 & SADSKPIDV & Aminoacyl tRNA synthase complex-interacting multifunctional protein 1 & + \\
\hline P20 & KLDETGNSL & DNA topoisomerase 2-alpha & ++ \\
\hline P21 & MADRGEARL & RecQ-mediated genome instability protein 2 & ++ \\
\hline P22 & AADFEIGHF & Nucleosome assembly protein 1-like 1 & + \\
\hline P23 & NADGKIISL & Bifunctional glutamate/proline-tRNA ligase & +++ \\
\hline P24 & AADGKGVVV & $60 S$ ribosomal protein $L 28$ & ++ \\
\hline P25 & AADKIHSSF & Plasminogen activator inhibitor 2 & ++++ \\
\hline P26 & NADAIVVKL & Staphylococcal nuclease domain-containing protein 1 & +++ \\
\hline P27 & NADTVSSKL & AP-2 complex subunit beta & +++ \\
\hline P28 & SAEKAPVSV & Transforming acidic coiled-coil-containing protein 1 & +++ \\
\hline P29 & QGDAVVLKI & Immunoglobulin superfamily member 8 precursor & +++ \\
\hline P30 & AADHYSQQM & Guanylate-binding protein 4 & + \\
\hline
\end{tabular}




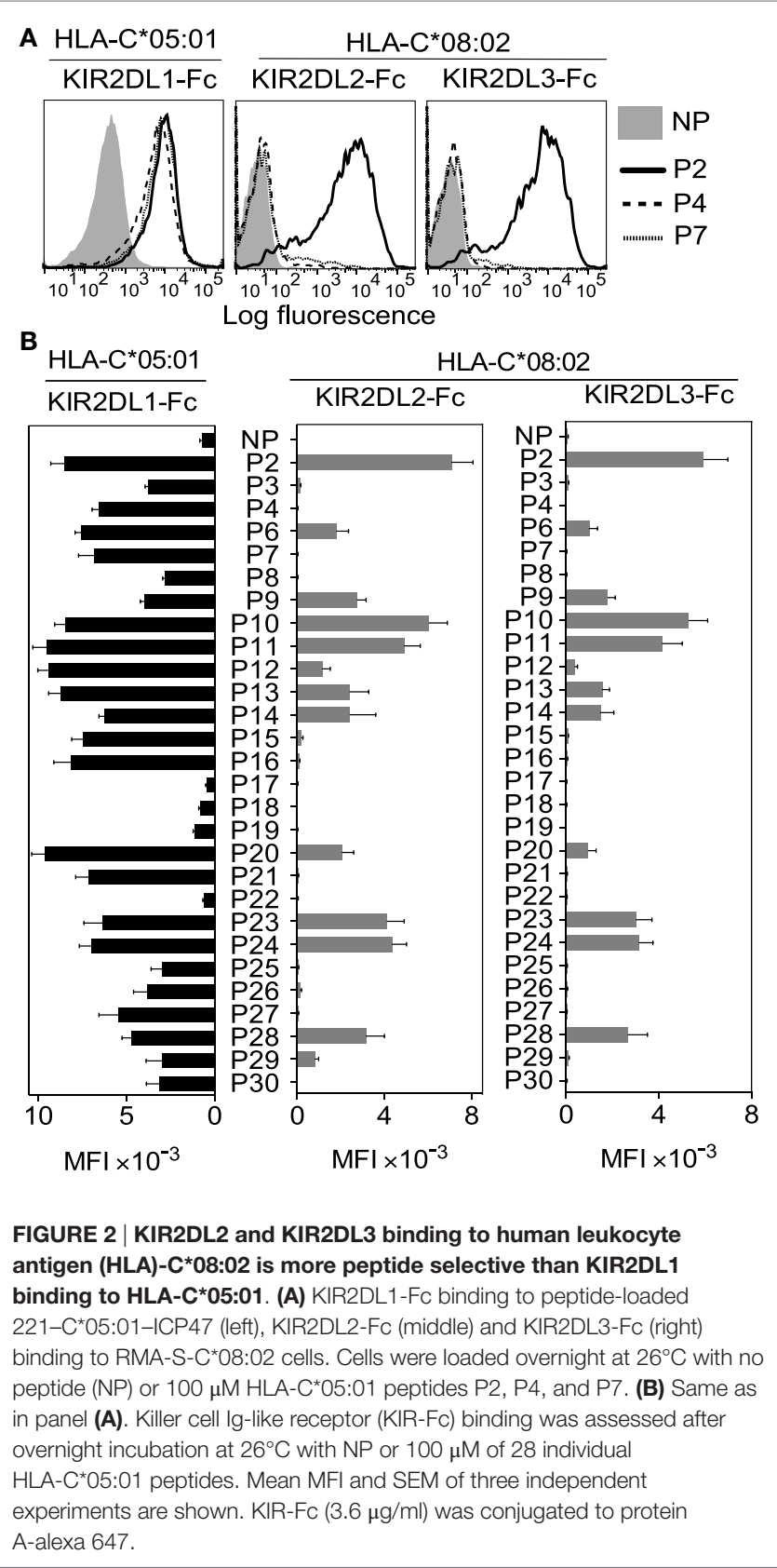

contradict their reported permissive, cross-reactive binding to group C2 HLA-C allotypes (26-28). The data suggest a fundamental difference between KIR binding to $\mathrm{C} 1$ and $\mathrm{C} 2$ allotypes. We next examined the contribution of peptide to KIR2DL2 and KIR2DL3 cross-reactive binding to HLA-C ${ }^{\star} 05: 01$ (C2).

\section{Cross-reactive KIR2DL2 and KIR2DL3 Binding to HLA-C*05:01 (C2) Is Highly Peptide Selective}

Cross-reactivity of HLA-C ${ }^{\star}$ 05:01 with KIR2DL2 and KIR2DL3 (27) was confirmed, showing KIR2DL1-Fc, KIR2DL2-Fc, and
KIR2DL3-Fc binding to $221-C^{\star} 05: 01$ cells (Additional File S3A-C in Supplementary Material). The strength of binding followed the hierarchy KIR2DL1 > KIR2DL2 > KIR2DL3. The same hierarchy was observed with another C2 allotype, HLA-C ${ }^{\star} 04: 01$ on $221-C^{\star} 04: 01$ cells, as reported previously (26, 27), despite weaker overall binding than that observed with 221-C $\mathrm{C}^{\star} 05: 01$ cells (Additional File S3A-C in Supplementary Material). Additionally, an NK cell line expressing KIR2DL3 (YTS-2DL3) was partially inhibited by $221-\mathrm{C}^{*} 05: 01$ in cytotoxicity assays, but not by $221-C^{\star} 04: 01$ (Additional File S3D,E in Supplementary Material). Inhibition of KIR2DL3 ${ }^{+}$cells was also tested with primary NK cells, using a gating strategy described in a previous study (33). Single-positive (SP) KIR3DL1, SP KIR2DL1, and SP KIR2DL3 cells degranulated strongly in response to untransfected 221 cells (Additional File S3F-H in Supplementary Material). Expression of HLA-C*05:01 on 221 cells had no impact on the degranulation of KIR3DL1-SP cells, while completely inhibiting the degranulation of KIR2DL1-SP NK cells and partially inhibiting KIR2DL3-SP NK cells (Additional File S3F-H in Supplementary Material). Thus, HLA-C ${ }^{\star} 05: 01$ is a functional ligand for KIR2DL1, KIR2DL2, and KIR2DL3.

Next we tested whether KIR2DL2 and KIR2DL3 crossreactivity resulted from weaker binding across all peptides or greater peptide selectivity. In marked contrast to KIR2DL1-Fc binding to HLA-C $\mathrm{C}^{\star}$ 05:01 (Figure 2B), only five peptides conferred cross-reactive binding to KIR2DL2-Fc and KIR2DL3-Fc (Figures 3A,B). Loading of peptides P2, P11, and P24, which have no amino acid in common at positions 7 and 8 (Table 1), resulted in the strongest binding. Thus, KIR2DL2 and KIR2DL3 cross-reactive binding to HLA-C ${ }^{\star} 05: 01$ was diminished, relative to that of canonical KIR2DL1, due to selective binding to a restricted subset of peptides.

Peptides that can promote cross-reactive KIR binding should occur by chance for every HLA-C allotype and can originate from endogenous host peptides as well as microbial pathogens. As an example, we tested five peptides derived from HIV Gag that stabilized HLA-I expression on $221-\mathrm{C}^{\star} 05$ :01-ICP47 cells. Two of them ( $\mathrm{Gag}^{60-68}$ and $\mathrm{Gag}^{310-318}$ ) promoted canonical binding of KIR2DL1, and one $\left(\mathrm{Gag}^{310-318}\right)$ promoted cross-reactive binding of KIR2DL2 and KIR2DL3 (Additional File S5A-E in Supplementary Material). These data provide a proof of principle that peptides of viral origin, similar to endogenously processed peptides, can promote cross-reactive KIR binding.

\section{Peptide Sequence Determines Canonical and Cross-reactive KIR2DL2 and KIR2DL3 \\ Binding}

We then compared the contribution of peptide sequence to canonical and cross-reactive KIR2DL2 and KIR2DL3 binding to HLA-C ${ }^{\star} 08: 02$ and HLA-C ${ }^{\star} 05: 01$, respectively (Figure 4). Peptide 2 (P2; IIDKSGSTV) promoted strong KIR2DL2 and KIR2DL3 binding to HLA-C $\mathrm{C}^{\star} 08: 02$ and HLA-C ${ }^{\star} 05: 01$ (Figure 2B; Additional File S4 in Supplementary Material). The role of peptide positions 7 and 8 in KIR binding to peptide 2 (P2; IIDKSGSTV)-loaded HLA-C was explored using amino 


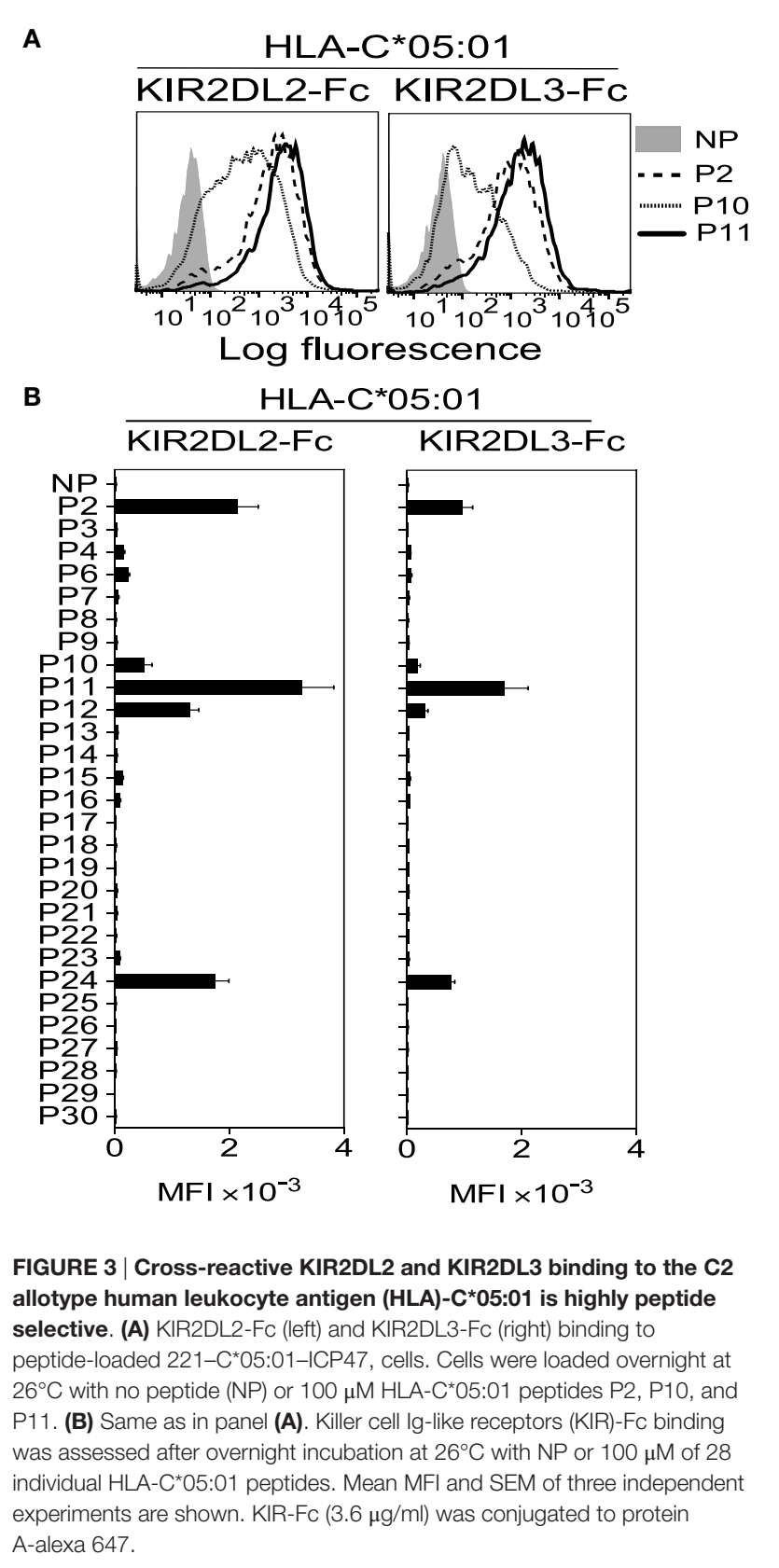

acid-substituted peptides, and binding was compared to that of canonical KIR2DL1 with HLA-C ${ }^{\star}$ 5:01 (Figure 4). All peptides with amino acid substitutions at positions 7 and 8 had a similar capacity to stabilize HLA-C expression as the parent peptide (Additional File S6A-C in Supplementary Material). We first tested the impact of decreasing the size of amino acid side chains by substituting Ser at position 7 and Thr at position 8 of peptide 2 with Ala, either singly (IIDKSG $\underline{A} T V$ and IIDKSGSA $\underline{V}$ ) or both (IIDKSGAAV). Each Ala-substituted peptide promoted enhanced and additive cross-reactive binding of KIR2DL2-Fc and KIR2DL3-Fc to HLA-C ${ }^{\star} 05: 01$, with a greater contribution from an Ala substitution at position 8 than position 7. In contrast, these substitutions had no impact on canonical binding to HLA- $C^{\star} 08: 02$ (Figure $4 A$ ). The strong binding promoted by IIDKSG $\underline{A A V}$ was not due simply to the small side chain size, as substitutions with Gly (IIDKSGGGV) abolished cross-reactive binding to HLA-C ${ }^{\star} 05: 01$ and substantially reduced canonical KIR2DL2 and KIR2DL3 binding to HLA-C ${ }^{\star} 08$ :02 (Figure 4A). The impact of increased side chain size at position 8 was then tested by replacing position 8 in P2-AA (IIDKSG $\underline{A A V}$ ) with Val

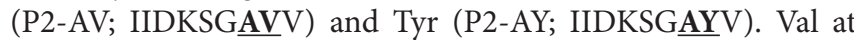
position 8 had little impact on KIR2DL2 and KIR2DL3 binding, whereas Tyr at position 8 almost abrogated binding, suggesting that a bulky side chain impeded binding. Consistent with these results, a previous study showed that KIR2DL2 binding to HLA$\mathrm{C}^{\star} 03: 04(\mathrm{C} 1)$ was sensitive to side chain size at position 8 , with a preference for side chains no larger than Val (25).

In a previous study, KIR2DL2 binding to HLA-C*01:02 was strongest with peptides having Leu or Phe at position 7 (19). We tested KIR2DL2 and KIR2DL3 binding to P2-AA (IIDKSGAAV) substituted with Leu (P2-LA; IIDKSGLAV) or Phe (P2-FA; IIDKSGFAV) at position 7 and found that P2-LA (IIDKSGLAV) promoted the strongest binding of all peptides tested when presented on HLA-C $C^{\star 08: 02}$ or HLA-C ${ }^{\star} 05: 01$. In contrast, P2-FA (IIDKSGFAV) promoted weaker binding, a decrease which was more marked in cross-reactive KIR2DL2 and KIR2DL3 binding to HLA-C $\mathrm{C}^{\star} 05: 01$, than in canonical binding to HLA-C ${ }^{\star} 08: 02$.

The strong cross-reactive binding of KIR2DL2 and KIR2DL3 to P11 (AGDDAPRAV, Figure 3) suggested a role for a positively charged residue at position 7 in binding. We tested this by substituting position 7 of P2-AA (IIDKSG $\underline{A}$ V) with Lys (P2-KA; IIDKSGKAV) or Arg (P2-RA; IIDKSGRAV). While P2-RA (IIDKSGRAV) promoted strong KIR2DL2 and KIR2DL3 binding, P2-KA (IIDKSGKAV) was weaker, suggesting that a positive charge alone is not sufficient for strong binding (Figure 4A). Replacement of position 8 with Glu (P2-8E; IIDKSGSEV) or positions 7 and 8 with Glu (P2-EE; IIDKSGEEV) completely abrogated KIR2DL2 and KIR2DL3 binding to both HLA-C ${ }^{\star} 08: 02$ and HLA-C ${ }^{\star}$ 05:01 (Figure 4A). This is consistent with our earlier results (Figure 2) and previous studies demonstrating that negatively charged sides chains at position 7 or 8 are not competent for binding $(19,20)$, which is likely due to charge repulsion with the negatively charged KIR-binding face (24). In sharp contrast to KIR2DL2 and KIR2DL3 binding, canonical KIR2DL1 binding to HLA-C ${ }^{\star}$ 05:01 was largely resistant to changes in amino acid sequence at position 7 or 8 except to those with acidic residues at position 7 or 8 , similar to our results (Figure 2 B) and previous studies (21).

\section{Contribution of Peptide Sequence at Positions 7 and 8 to KIR Binding Is Dependent on Peptide Context}

Canonical and cross-reactive KIR2DL2 and KIR2DL3 binding showed some similarities in preference for amino acids at positions 7 and 8. However, peptide 10 (P10; IVDKSGRTL) promoted strong KIR2DL2 and KIR2DL3 binding to HLA-C ${ }^{\star} 08: 02$, 

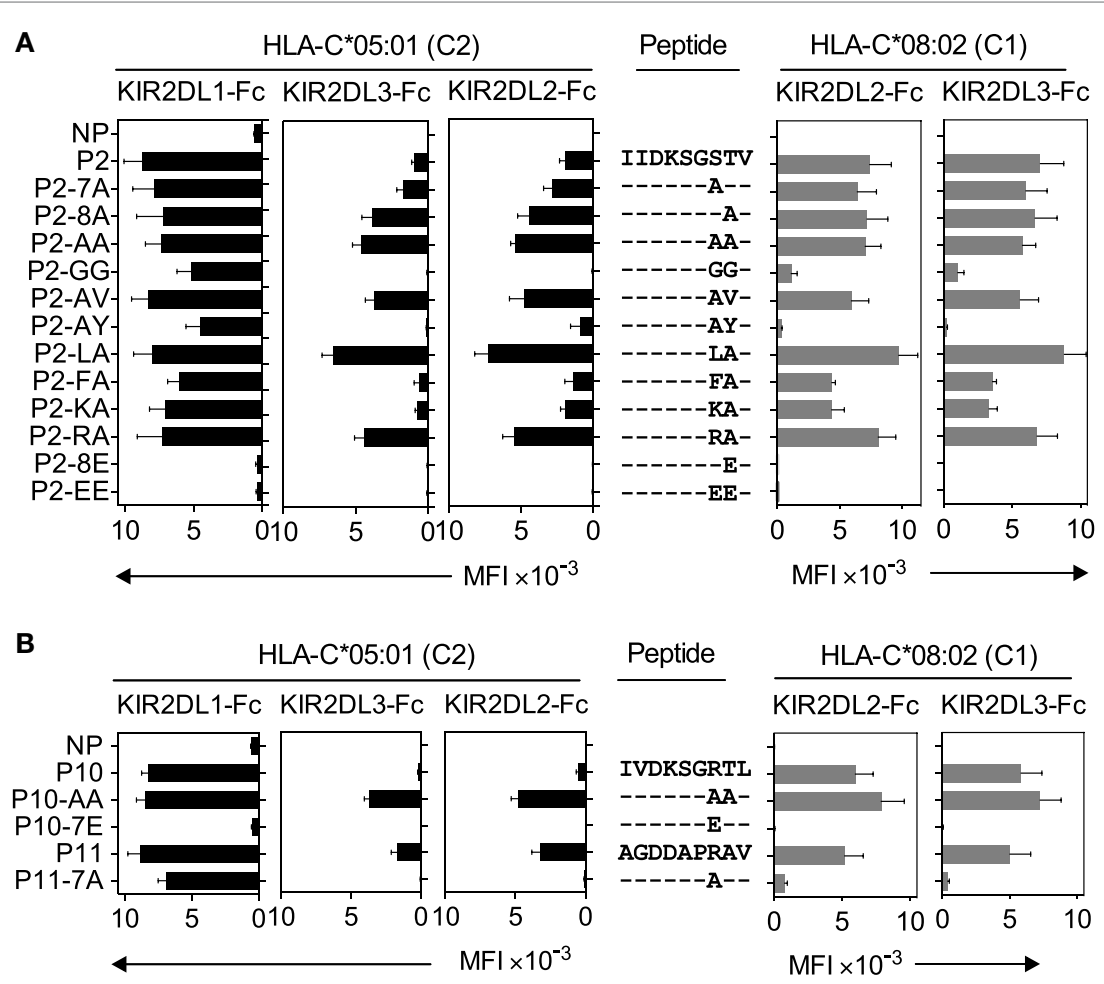

FIGURE 4 | Canonical and cross-reactive KIR2DL2 and KIR2DL3 binding is controlled by amino acids at positions 7 and 8. (A) KIR2DL1-FC, KIR2DL2Fc, and KIR2DL3-Fc binding to peptide-loaded 221-C*05:01-ICP47 (left, black) and KIR2DL2-Fc and KIR2DL3-Fc (right, gray) binding to RMA-S-C*08:02 cells. Cells were loaded overnight at $26^{\circ} \mathrm{C}$ with no peptide (NP) or $100 \mu \mathrm{M}$ of peptide P2 (P2-IIDKSGSTV) and amino acid variants of peptide 2 with substitutions at positions 7 and 8. Amino acid sequence substitutions at positions 7 and 8 are shown. Mean MFI and SEM of three independent experiments are shown. Killer cell Ig-like receptors (KIR-Fc, $3.6 \mu \mathrm{g} / \mathrm{ml}$ ) were conjugated to protein A-alexa 647. (B) KIR2DL1-Fc, KIR2DL2-Fc, and KIR2DL3-Fc binding to peptide-loaded 221$\mathrm{C}^{\star}$ 05:01-ICP47 (left, black) and KIR2DL2-Fc and KIR2DL3-Fc (right, gray) binding to RMA-S-C*08:02 cells. Cells were loaded overnight at $26^{\circ} \mathrm{C}$ with NP or $100 \mu \mathrm{M}$ of peptides P10 (P10-IVDKSGRTL), P11 (P11-AGDDAPRAV), and amino acid variants of P10 and P11 with substitutions at positions 7 and 8 . Amino acid sequence at positions 7 and 8 is shown. Mean MFI and SEM of three independent experiments are shown. KIR-FC (3.6 $\mu \mathrm{g} / \mathrm{ml})$ was conjugated to protein A-alexa 647 .

but weaker cross-reactive binding to HLA-C ${ }^{\star}$ 05:01 (Figure 2B; Additional File S4 in Supplementary Material). In contrast, peptide 11 (P11; AGDDAPRAV) with similar side chains at positions 7 and 8 conferred canonical and cross-reactive binding. P10 and P11 share an Arg at position 7 and have small amino acids at position 8 , both of which are compatible with canonical and cross-reactive binding (Figure 4B). These results suggest that factors other than side chains at positions 7 and 8 impact on KIR2DL2 and KIR2DL3 binding. To examine this further, residues at positions 7 and 8 of P10 and P11 were substituted with Ala (P10-AA; IVDKSG $\underline{\mathbf{A A L}}$ and P11-7A; AGDDAP吕AV), a combination that promoted strong canonical and cross-reactive binding in the context of P2 (Figure 4A). These substitutions had opposite effects for P10 and P11 (Figure 4B). P10-AA (IVDKSG $\underline{\mathbf{A A L}}$ ) was similar to P2-AA (IIDKSGAAV), promoting strong cross-reactive binding and maintaining strong canonical binding. In contrast, P11-7A (AGDDAPAAV) promoted almost no KIR2DL2 and KIR2DL3 binding, be it canonical or cross-reactive (Figure 4B). In summary, Arg at position 7 is competent for KIR2DL2 and KIR2DL3 cross-reactive binding in the context of P2 or P11, but not P10. Ala at positions 7 and 8 was competent for KIR2DL2 and
KIR2DL3 binding in the context of P2 and P10, but not P11. Therefore, KIR2DL2 and KIR2DL3 binding to $\mathrm{HLA}^{\star} \mathrm{C}^{\star}$ 05:01 and HLA-C ${ }^{\star}$ 08:02 appears to be dependent on side chains at positions 7 and 8 , but the contribution of specific amino acids at positions 7 and 8 is valid only in the context of a given 9 mer. In contrast, KIR2DL1 binding to HLA-C ${ }^{\star} 05: 01$ is strong in the presence of the majority of peptide variants accommodating various amino acid side chains, apart from those containing acidic residues (Figures 4A,B). Overall, the impact of amino acids at positions 7 and 8 on KIR2DL2 and KlR2DL3 binding was similar in the context of HLA-C ${ }^{\star} 08: 02$ and $\mathrm{HLA}^{-} \mathrm{C}^{\star}$ 05:01 with a strong correlation in the presence of the same peptides $(r=0.8712, p<0.0001$; Additional File S6D in Supplementary Material). Cross-reactive binding of KIR2DL2 and KIR2DL3 was more peptide selective than canonical binding.

Together, these data provide support for an argument that KIR2DL2 and KIR2DL3 canonical binding to HLA-C*08:02 is more peptide selective than that of KIR2DL1 to HLA-C ${ }^{\star} 05: 01$, that cross-reactive binding to HLA-C ${ }^{\star} 05: 01$ is even more peptide selective, and that binding is dependent on a combination of different side chains at positions 7 and 8 within a given peptide sequence context. 


\section{High Peptide Selectivity in Functional Inhibition of KIR2DL3+ NK Cells by Cross- reactivity with $\mathrm{HLA}-\mathrm{C}^{*} 05: 01$ (C2)}

We tested the capacity of KIR2DL2 and KIR2DL3 cross-reactive peptides to inhibit KIR2DL3 ${ }^{+}$NK cells when presented on HLA$C^{\star} 05: 01$. YTS cells expressing KIR2DL3 (YTS-2DL3) were tested for inhibition by $221-C^{\star} 05: 01-I C P 47$ cells that had been loaded with peptides. Inhibition of YTS-2DL3 cytotoxicity correlated well with the binding of KIR2DL3-Fc to HLA-C ${ }^{\star}$ 05:01 (Figure 5). Strong inhibition was obtained with P2-AA (IIDKSGAAV), and partial inhibition with P2 (Figures 5A,B). Loading of peptides that did not promote KIR2DL3 binding to HLA-C*05:01 (P2GG, IIDKSGGGV; P2-EE, IIDKSGEEV; or P7, YVDEHGTRL) did not result in inhibition (Figures $\mathbf{5 A}, \mathbf{B}$ ). Inhibition of primary human NK cells was tested in degranulation assays. KIR2DL3-SP NK cells degranulated strongly in response to 221-C*05:01-ICP47 cells that had not been loaded with peptide (Figures 5C,D). 221-C05:01-ICP47 cells loaded with weaker binders such as peptides P2, P11, or P10 induced partial inhibition (Figures 4 and 5D), while those loaded with strong binders such as peptides P2-LA (IIDKSGLAV), P2-AA (IIDKSG or P10-AA (IVDKSGAAL) induced strong inhibition (Figures 4 and 5D). While 221-C $\mathrm{C}^{\star 05: 01-I C P 47}$ cells loaded peptides that did not promote binding such as P2-GG (IIDKSGGGV), P2-EE (IIDKSGEEV), P11-7A (AGDDAPAAV), and P10-7E (IVDKSGETL) induced as much degranulation as cells in the absence of peptide (Figures 4 and 5D). There was a strong inverse correlation between KIR2DL3-Fc binding to and degranulation of KIR2DL3-SP NK cells in response to 221-C05:01-ICP47 cells loaded with the same peptides (Figure 5E).

As an internal control, degranulation of KIR3DL1-SP NK cells was not impacted by the presence of any of the peptides (Figure 5C; Additional File S7 in Supplementary Material). Thus, we have shown that the group C2 allotype, HLA-C ${ }^{\star} 05: 01$ loaded with peptide that confers binding to KIR2DL3 induces functional inhibition of KIR2DL3 ${ }^{+} \mathrm{NK}$ cells.

\section{Functional Cross-reactive KIR2DL1 Binding to the C1 Allotype, HLA-C*08:02}

KIR2DL1 is highly specific for the C2 allotypes (3). We put this specificity to the test by examining KIR2DL1 binding to HLA$\mathrm{C}^{\star} 08: 02$ (C1) after loading with the same peptide panel that had been used to test canonical binding to HLA-C ${ }^{\star} 05: 01$. We found two peptides that promoted KIR2DL1 binding to HLA-C ${ }^{\star} 08: 02$ (C1), peptides P10 (IVDKSGRTL) and P11 (AGDDAPRAV) (Figure 6A). For peptide P10, this KIR2DL1 cross-reactive binding was about twofold to threefold weaker than KIR2DL3 binding to HLA-C ${ }^{\star} 08: 02$ (Figures 2 and 6A). Peptides P10 (P10IVDKSGRTL) and P11 (P11-AGDDAPRAV) share an Arg at position 7, and KIR2DL1 binding to HLA-C ${ }^{\star} 08$ :02 was lost when Arg at position 7 of peptide P11 (P11-AGDDAPRAV) was replaced by Ala (P11-7A; AGDDAPAAV) (Figures 6A,B). To further test whether Arg at position 7 contributed to cross-reactive binding of KIR2DL1 to HLA-C*08:02, an Arg was substituted for the Ala
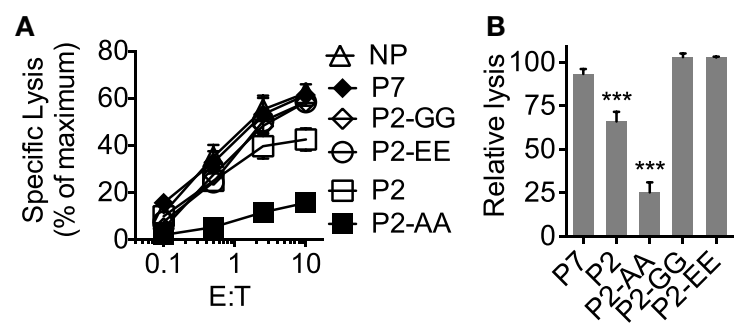

C KIR2DL3-SP KIR3DL1-SP
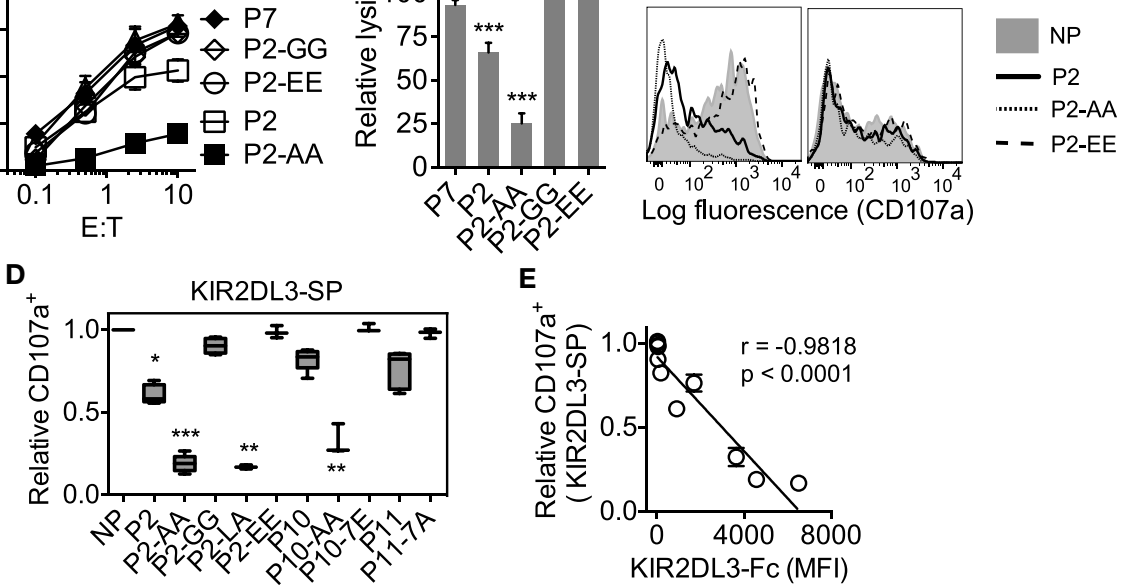

FIGURE 5 | High peptide selectivity, cross-reactive binding and functional inhibition of KIR2DL3 ${ }^{+}$natural killer (NK) cells by HLA-C*05:01 (C2). (A) Specific lysis of 221-C*05:01-ICP47 cells at different E:T by YTS-2DL3 NK cells. 221-C*05:01-ICP47 target cells were used after overnight culture at $26^{\circ} \mathrm{C}$ in the presence of no peptide (NP), P2, P2-AA, P2-EE, P2-GG, and P7. (B) Relative-specific lysis of 221-C*05:01-ICP47 cells by YTS-2DL3 NK cells compared to NP at10:1 (E:T). Mean and SEM of three independent experiments are shown. ${ }^{\star \star \star}=p<0.001$ by Student's $t$-test. (C) Flow cytometry histograms showing degranulation (CD107a expression) of KIR2DL3-SP (left) and KIR3DL1-SP (right) NK cells in response to 221-C*05:01-ICP47 cells loaded with P2, P2-AA, P2-EE, or NP. (D) Box plots showing the fraction of CD107a+ KIR2DL3-SP NK cells in response to 221-C*05:01-ICP47 cells loaded with P2, P2-AA, P2-EE, P2-GG, P2-LA, P11, P11-7A, P10, P10-AA, P10-7E, or NP $(n=3-5)$. The CD107a+ values were normalized to the fraction of CD107a+ KIR2DL3-SP NK cells that degranulated in the absence of peptide (set at 1.0) for each donor (CD107a ${ }^{+}$ranged from 62.8 to $79.0 \%, n=5$ ). ${ }^{* \star *} p<0.001,{ }^{* \star} p<0.01$, and ${ }^{*} p<0.05$ by Kruskal-Wallis test with Dunn's multiple comparisons test. (E) KIR2DL3-Fc binding to 221-C*05:01-ICP47 cells correlated with degranulation (CD107a ${ }^{+}$) of KIR2DL3-SP NK cells in response to 221-C*05:01-ICP47 cells in the presence of P2, P2-AA, P2-EE, P2-GG, P2-LA, P11, P11-7A, P10, P10-AA, P10-7E, or NP. Spearman's correlation $r=-0.955, p<0.0001$. CD107a expression was normalized to value obtained in response to NP for each donor. 


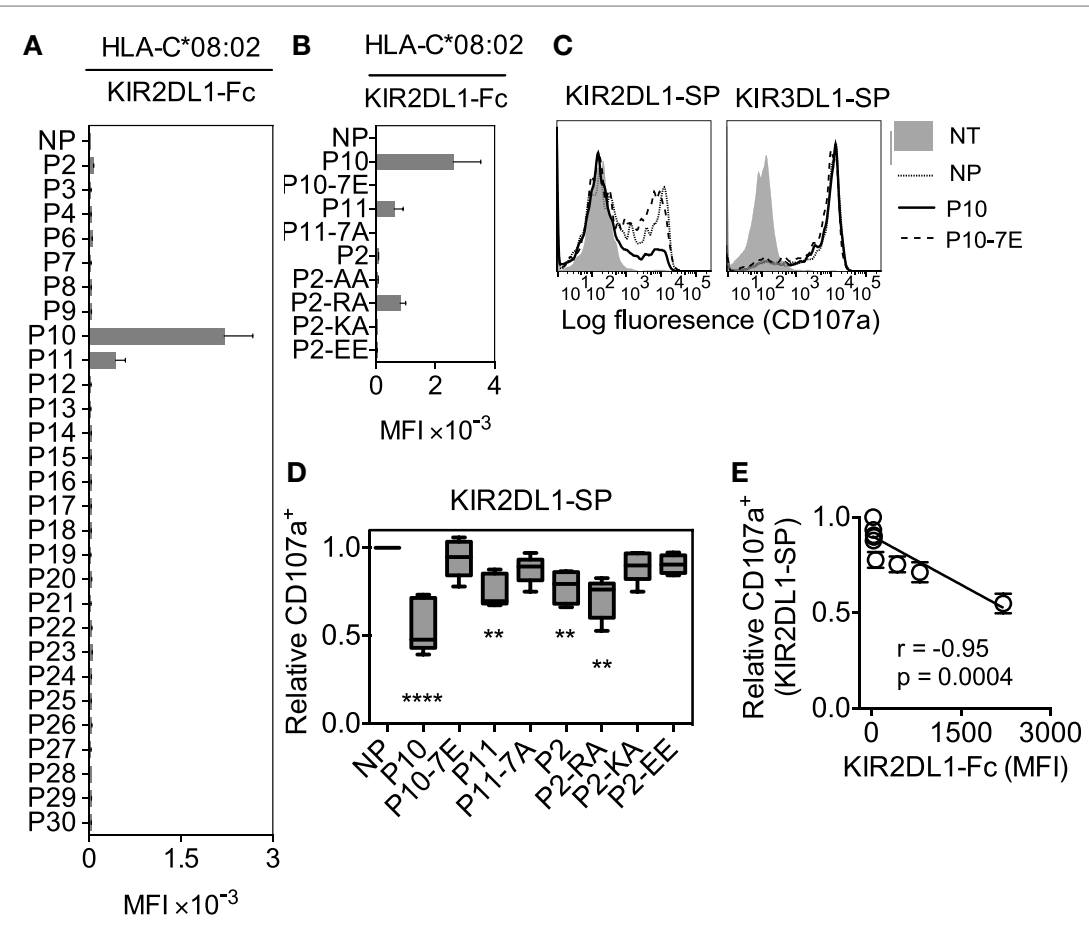

FIGURE 6 | High peptide selectivity and functional cross-reactive binding of KIR2DL1 to the C1 allotype human leukocyte antigen (HLA)-C*08:02. (A) KIR2DL1-Fc binding to RMA-S-C*08:02 cells after overnight incubation at $26^{\circ} \mathrm{C}$ with no peptide (NP) or $100 \mu \mathrm{M}$ of 28 individual HLA-C*05:01 peptides. Mean MFI and SEM of three independent experiments are shown. (B) KIR2DL1-Fc binding to RMA-S-C*08:02 cells after overnight incubation at $26^{\circ} \mathrm{C}$ with $\mathrm{NP}$ or $100 \mu \mathrm{M}$ of peptides P10, P10-7E, P11, P11-7A, P2, P2-AA, P2-RA, P2-KA, and P2-EE. Mean MFI and SEM of three independent experiments are shown. KIR-Fc (3.6 $\mu \mathrm{g} / \mathrm{ml})$ was conjugated to protein A-alexa 647. (C) Flow cytometry histograms showing degranulation (CD107a expression) of KIR2DL1-SP (left) and KIR3DL1-SP (right) natural killer (NK) cells in response to 221-C*08:02-ICP47 cells pre-incubated overnight with P10, P10-7E, or NP. Expression of CD107a on KIR2DL1-SP NK cells with no target cells is also shown. (D) Box plots showing CD107a expression on KIR2DL1-SP NK cells in response to 221-C*08:02-ICP47 cells pre-incubated overnight with P10, P10-7E, P11, P11-7A, P2, P2-RA, P2-KA, P2-EE, or NP $(n=5-8)$. The CD107a ${ }^{+}$values were normalized to the fraction of CD107a ${ }^{+}$KIR2DL1SP NK cells that degranulated in the absence of peptide (set at 1.0) for each donor (CD107a+ ranged from 23.7 to $68.4 \%, n=8$ ). ${ }^{\star \star \star *} p<0.0001$ and ${ }^{* \star} p<0.01$ by Kruskal-Wallis test with Dunn's multiple comparisons test. (E) KIR2DL1-Fc binding to RMA-S-C*08:02 cells is correlated with degranulation (CD107a+) of KIR2DL1-SP NK cells in response to 221-C*08:02-ICP47 cells loaded with P10, P10-7E, P11, P11-7A, P2, P2-RA, P2-KA, P2-EE, or NP. CD107a expression was normalized to value obtained in response to NP for each donor. Spearman's correlation, $p=0.0004, r=-0.95$.

at position 7 of the non-binding peptide P2-AA (IIDKSG $\underline{A A V}$ ).

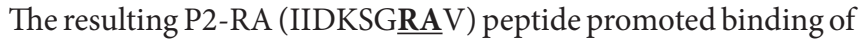
KIR2DL1 to HLA-C ${ }^{\star}$ 08:02 (Figures 6A,B). This Arg-dependent gain-of-function was not reproduced with a Lys at position 7 (P2-KA; IIDKSGKAV, in Figures 6A,B), suggesting specific recognition of Arg at position 7 by KIR2DL1 in the context of HLA-C ${ }^{\star}$ 08:02.

To test whether cross-reactive KIR2DL1 binding to HLA$\mathrm{C}^{\star}$ 08:02 resulted in functional inhibition of NK cytotoxicity, we generated 721.221 cells expressing HLA-C ${ }^{\star} 08: 02$ (221- $C^{\star} 08: 02$; Additional File S8A,B in Supplementary Material), which were further transfected with the TAP inhibitor ICP47 (221-C*08:02ICP47). KIR2DL1-Fc bound 221-C*08:02-ICP47 cells that had been loaded with P10 (P10-IVDKSGRTL) (Additional File S8C in Supplementary Material). In assays using primary NK cells, KIR2DL1-SP NK cells degranulated in response to $221-C^{\star} 08: 02-$ ICP47 cells not loaded with peptide (Figures 6C,D). Loading of 221-C*08:02-ICP47 cells with peptide P10 (P10-IVDKSGRTL) resulted in inhibition of degranulation by KIR2DL1-SP cells, but not KIR3DL1-SP cells (Figure 6C). As expected, replacement of Arg at position 7 with Glu, P10-7E (IVDKSGETL) that impeded binding also eliminated inhibition (Figures 6B-D). We conclude that cross-reactive binding of KIR2DL1 to HLA$C^{\star}$ 08:02 loaded with peptide P10 (P10-IVDKSGRTL) resulted in functional inhibition of NK cell degranulation. While peptide P10 (P10-IVDKSGRTL) was compatible with canonical binding of KIR2DL1, KIR2DL2, and KIR2DL3 (Figure 2) and with cross-reactive KIR2DL1 binding to $\mathrm{HLA}^{-} \mathrm{C}^{\star}$ 08:02 (Figure 6A), it formed a less effective ligand for cross-reactive binding of KIR2DL2 and KIR2DL3 to HLA-C ${ }^{\star} 05: 01$ (Figure 3). Weak inhibition of degranulation by KIR2DL1-SP NK cells was detected with $221-C^{\star} 08: 02-I C P 47$ cells loaded with peptides that promoted weak KIR2DL1 binding, P11 (AGDDAPRAV) and P2-RA (IIDKSGRAV) (Figure 6D). Replacement of the Arg at position 7 of P2-RA (IIDKSGRAV) by Lys P2-KA (IIDKSGKAV) eliminated inhibition, as expected from the loss of binding (Figure 6B). Similar to KIR2DL3 with HLA-C ${ }^{\star} 05: 01$, there was a strong inverse correlation between KIR2DL1-Fc binding to and degranulation of KIR2DL1-SP cells in response to 221- ${ }^{\star} 08: 02-$ ICP47 cells (Figure 6E). Degranulation of KIR3DL1-SP NK cells 
was not inhibited by any of the peptides (Figure 6C; Additional File S8D in Supplementary Material). The ratio of KIR-Fc binding (as mean fluorescence intensity) to the extent of degranulation (as a fraction of each SP cell subset) was similar for KIR2DL1 with HLA-C ${ }^{\star}$ 08:02 and KIR2DL3 with HLA-C ${ }^{\star}$ 05:01 (Additional File S8E in Supplementary Material). We conclude that the highly peptide-selective binding of KIR2DL1 to the group C1 allotype HLA-C ${ }^{\star} 08: 02$ was competent to induce functional inhibition of KIR2DL1 ${ }^{+}$NK cells.

\section{DISCUSSION}

Disease associations with different combinations of KIR and HLA-C genes have been interpreted through the "strength of inhibition" hypothesis, which posits that KIR2DL1 binding to a $\mathrm{C} 2$ allotype is a stronger interaction than KIR2DL3 with C1 $(3,6-8,10-15,34)$ This hypothesis is based on the weaker binding of soluble KIR2DL3-Fc fusion protein to $\mathrm{C} 1$ compared to KIR2DL1-Fc binding to C2, using HLA-C ${ }^{+}$cells or HLA-C molecules attached to beads $(27,28,35)$. Weaker interactions have been interpreted as potentially beneficial in viral infections such as $\mathrm{HCV}$ due to reduced inhibition of NK cells in individuals homozygous for C1 and for KIR2DL3 (9). Conversely, disorders of pregnancy in mothers carrying a C2/ C2 fetus and expressing KIR2DL1 on uterine NK cells have been interpreted as being due to stronger inhibition by KIR2DL1, resulting in decreased activation of specialized uterine NK cells that promote vascular remodeling to increase blood supply to the fetus $(10,11,36,37)$. However, the strength of inhibition hypothesis has to be reconciled with direct measurements of KIR binding to HLA-C in solution. Dissociation constants for KIR2DL1 with C2, and for KIR2DL2 and KIR2DL3 with $\mathrm{C} 1$, have been similar, ranging from 6.9 to $11.2 \mu \mathrm{M}(25,38$, 39). These measurements, obtained with recombinant HLA-C molecules that had been refolded with one peptide at a time, do not capture the complexity of KIR binding to cells expressing HLA-C molecules associated with a large repertoire of peptides. By examining how HLA-C-bound peptides regulate binding of KIR, we provide an explanation for the difference between solution binding measurements and strength of inhibition and demonstrate a hierarchy in the contribution of both HLA-C allotype and peptide sequence to KIR-HLA-C interactions (Figure 7). Our findings have direct implications for NK biology and human disease associations.

We took advantage of the sequence identity of HLA-C $\mathrm{C}^{\star}$ 05:01 (group C2) and HLA-C*08:02 (group C1) in all but for the two amino acids that define group $\mathrm{C} 1$ and $\mathrm{C} 2$ allotypes and specificity of KIR2DL1-C2 and KIR2DL2/3-C1 binding. This allowed us to specifically compare binding of KIR to $\mathrm{C} 1$ and $\mathrm{C} 2$ allotypes loaded with the same, single set of peptides. We eluted peptides from HLA-C ${ }^{\star}$ 05:01 and showed that individual peptides could stabilize both HLA-C ${ }^{\star}$ 05:01 and HLA-C $C^{\star} 08: 02$ at the surface of TAP-deficient cells. Our hypothesis and conclusions do not rely on the assumption that HLA-C ${ }^{\star} 08: 02$ has the same repertoire of endogenous peptides as those eluted from HLA-C ${ }^{\star} 05: 01$. We show that KIR2DL2/3 binding to $\mathrm{C} 1$ is more selective for specific HLA-C-peptide complexes than KIR2DL1-C2, providing an explanation for the observation that KIR2DL3-C1 interactions appear to be weaker than KIR2DL1-C2.

KIR2DL1 bound to C2 allotype HLA- $C^{\star} 05: 01$ in the context of most peptides tested. In addition, we show that the peptide selectivity of KIR2DL2/3 binding was greater in the context of cross-reactive binding to the $\mathrm{C} 2$ allotype HLA- $\mathrm{C}^{\star} 05: 01$. Crossreactive binding of KIR to non-canonical HLA-C allotypes has been described for KIR2DL2 and KIR2DL3 $(26,27)$. In the crystal structure of a KIR2DL2-HLA-C ${ }^{\star}$ 03:04 complex the peptide side chains at positions 7 and 8 are both orientated upwards toward the KIR and are both making contacts (25), whereas peptide made no direct contribution to binding in the crystal structure of a KIR2DL1-HLA-C ${ }^{\star}$ 04:01 complex (24). This is consistent with our data demonstrating a greater contribution of peptide sequence to canonical KIR2DL2/3 binding with $\mathrm{C} 1$ than to KIR2DL1 binding to C2.

The peptide sequence-dependent binding of KIR to HLA-C described here contrasts with the prevailing view that peptide selectivity of KIR binding to HLA-C is due mainly to peptide side chains at positions 7 and 8 of 9 mers that interfere with binding through their bulk or charge $(21,25)$. Furthermore, KIR2DL2 and KIR2DL3 binding is not governed simply by amino acids at positions 7 and 8. For example, replacing Arg-Ala at those positions in the peptide P2 with Ala-Ala did not affect KIR2DL2 and KIR2DL3 canonical binding to $\mathrm{C} 1$ or cross-reactive binding to C2. The same Arg-Ala to Ala-Ala substitution in peptide P11 eliminated binding of KIR2DL2 and KIR2DL3 to both C1 and C2 allotype. Finally, peptide P10 with Arg-Thr at positions 7 and 8 , which promoted strong KIR2DL2 and KIR2DL3 canonical binding, but weaker cross-reactive binding, gained strong crossreactive binding to HLA-C*05:01 when changed to Ala-Ala. Thus the contribution of positions 7 and 8 to binding of KIR2DL2 and KIR2DL3 is clearly tied to additional features of the peptide.

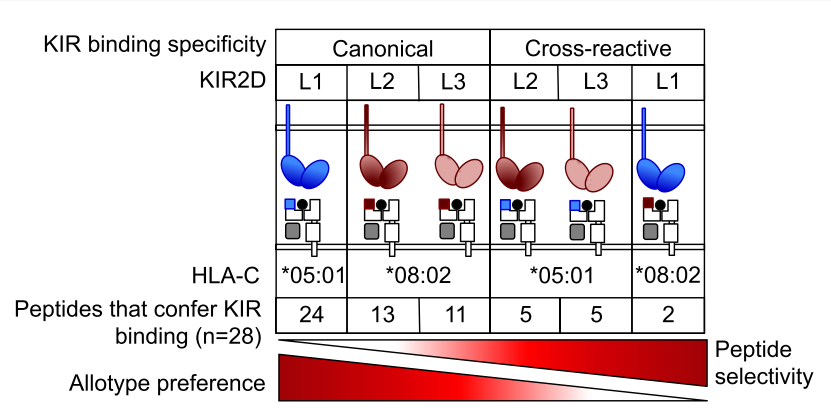

FIGURE 7 | KIR2DL2 and KIR2DL3 are more peptide selective than KIR2DL1 but less stringent about allotype preference. KIR2DL1, with strong specificity for C2 allotype, exhibits low peptide selectivity in binding C2. KIR2DL2 and KIR2DL3 cross-reactivity with C2 is associated with greater peptide selectivity. KIR2DL1 cross-reacted with $\mathrm{C} 1$ in the context of only two peptides. This hierarchy in peptide selectivity of killer cell lg-like receptors (KIR)-HLA-C interactions is relevant to natural killer (NK) biology and understanding of disease associations. Peptide sequence-driven binding of KIR to HLA-C provides a potential mechanism for pathogen as well as self-peptide to modulate NK cell function through altering levels of KIR binding and KIR-mediated inhibition. 
KIR2DL1 has strong selectivity for C2 allotypes. Weak cross-reactive binding of KIR2DL1 was reported with group C1 HLA-Cw7 loaded with a single peptide but was not tested functionally $(38,39)$. We show here that two peptides loaded on the $\mathrm{C} 1$ allotype HLA-C ${ }^{\star}$ 08:02 promoted KIR2DL1 binding, which resulted in functional inhibition of KIR2DL1+ $\mathrm{NK}$ cells. The crystal structure of a canonical KIR2DL1-HLA-C*04:01 complex revealed a binding site made largely of shape complementarity and of electrostatic forces between a positively charged HLA-C molecule and a negatively charged KIR (24). Lys $^{80}$ of HLA-C ${ }^{\star} 04: 01$ is accommodated by a specific pocket in KIR2DL1, in which $\mathrm{Met}^{44}$, Ser ${ }^{184}$, and $\mathrm{Glu}^{187}$ interact directly with HLA-C. The peptide made no direct contribution to binding, which may explain why KIR2DL1 binds to HLA-C*04:01 and, as shown here, to HLA-C ${ }^{\star} 05: 01$ in the context of most peptides $(21,24)$. It is also consistent with the notion that KIR2DL1 and C2 allotypes have coevolved more recently than KIR2DL2/3 with $\mathrm{C} 1$ allotypes as a more stringent KIR-HLA-C combination (29). Cross-reactive KIR2DL1 binding to HLA-C ${ }^{\star} 08: 02$ occurred only with peptides carrying Arg at position 7, suggesting that an Arg at position 7 may compensate for the absence of the C2-defining Lys ${ }^{80}$.

Our data suggest a hierarchy in the contribution of both HLA-C allotype and peptide sequence in KIR binding (Figure 7). KIR2DL1, with strong specificity for C2 allotypes, binds C2 in the presence of most peptides. That peptide sequence contributes minimally to KIR2DL1 binding to C2 (21) is consistent with a lack of peptide contacts in the KIR2DL1-HLA-C*04:01 crystal structure (24). Together with the greater propensity of KIR2DL2/3 to cross-react with C2 than KIR2DL1 with C1, the data suggest a more fundamental difference between KIR2DL2/3 and KIR2DL1 binding to HLA-C, in which specificity for HLA-C allotype is inversely correlated with selectivity for peptides (Figure 7).

The use of HLA-C ${ }^{\star}$ 05:01 and HLA-C ${ }^{\star}$ 08:02 allotypes in our study has made it possible to examine and compare binding of KIR to a $\mathrm{C} 2$ and a $\mathrm{C} 1$ allotype in the context of the same peptides. There is a very large number of KIR combinations with HLA-C allotypes due to extensive polymorphism of $\operatorname{KIR}$ (29, 40-42) and of HLA-C. Canonical and cross-reactive binding of KIR to HLA-C and the contribution of peptide to the interaction may vary among different KIR-HLA-C combinations. KIR2DL2 and KIR2DL3 cross-reactive binding with $\mathrm{C} 2$ indeed varies among C2 allotypes (27).

The high polymorphism of the HLA-C peptide binding site is such that different HLA-C allotypes within group C1 or C2 present very different peptide repertoires. Therefore, a specific and conserved recognition of an HLA-C-peptide complex cannot be achieved by innate receptors such as KIR, which bind to a large number of HLA-C allotypes. Peptides that promote cross-reactive KIR binding should occur with a given probability for each HLA-C allotype and originate from endogenous host proteins as well as microbial pathogens. As an example, of five peptides from HIV Gag that were predicted to bind HLA-C ${ }^{\star} 05: 01$, two promoted canonical binding of KIR2DL1, one of which also promoted cross-reactive binding of KIR2DL2 and KIR2DL3. Similarly, a screen of peptides from two HCV proteins identified a 9mer sequence that promoted stronger binding of KIR2DL3 to HLA-C ${ }^{\star}$ 03:04 than binding obtained with an endogenous peptide known to be associated with HLA-C ${ }^{\star} 03: 04$ (43). These results illustrate the broader principle of immune subversion by intracellular pathogens capable of generating peptides that bind HLA-C and modulate inhibitory KIR binding. Previous studies have reported HIV escape mutations that were associated with the presence of specific KIR genes, suggesting NK-mediated immune pressure on HIV (23). There was increased KIR binding to, and NK cell inhibition by, cells infected with viruses carrying the KIR-associated escape mutant. One of the HIV escape mutant peptides has been identified as a p24 Gag epitope, which promoted greater KIR2DL3 canonical binding to HLA-C ${ }^{\star}$ 03:04 than that of the original HIV Gag sequence (22). It is remarkable that the difference in binding to a single peptide can have an impact on KIR binding to cells that express a large repertoire of HLA-C-peptide complexes. Analysis of peptide repertoires on virus-infected cells is needed to better understand viral evasion through inhibition of NK cells. As we have shown here, the specificity of KIR for HLA-C is such that a single amino acid change in the peptide can be sufficient to cause large differences in KIR binding and KIR-mediated inhibition, including cross-reactive KIR binding to a non-canonical HLA-C allotype.

A peptide that promotes strong KIR cross-reactivity could push NK cells that are normally unlicensed to a more licensed state through non-canonical KIR-HLA-C binding. This could occur in $\mathrm{C} 1 / \mathrm{C} 1$ and $\mathrm{C} 2 / \mathrm{C} 2$ homozygotes, as in either case SP KIR2DL1 ${ }^{+} \mathrm{NK}$ cells and SP KIR2DL2 ${ }^{+}$or KIR2DL3 ${ }^{+} \mathrm{NK}$ cells, respectively, lack a canonical HLA-C ligand. Immune pressure by NK cells may select for viral peptides that promote crossreactivity, given that unlicensed NK cells, which include cells with orphan inhibitory receptors, have been shown to provide stronger antiviral responses than licensed NK cells in MCMVinfected and influenza virus-infected mice, and in EBV-infected humanized mice (44-47). According to this model, it would be harder for pathogens to evade SP KIR2DL1 ${ }^{+} \mathrm{NK}$ cells in $\mathrm{C} 1 /$ $\mathrm{C} 1$ individuals than SP KIR2DL3 ${ }^{+} \mathrm{NK}$ cells in $\mathrm{C} 2 / \mathrm{C} 2$, as the KIR2DL1-C1 cross-reactive combination is less prone to peptide sequence-dependent modulation. The new insights gained by our study suggest that interpretation of disease associations with KIR and $\mathrm{C} 1$ or $\mathrm{C} 2$ genes requires a better appreciation of the contribution of HLA-C-associated peptides to KIR binding and NK cell function.

\section{MATERIALS AND METHODS}

\section{Study Design}

The goal of the study was to investigate the contribution of HLA-C bound peptides to canonical and cross-reactive KIR binding to $\mathrm{C} 1$ and $\mathrm{C} 2$ allotypes. In vitro experiments were carried out to test the level of soluble KIR-Fc binding to peptide-loaded HLA-C on TAP-deficient cells by flow cytometry. Experiments were repeated at least three times, and KIR-Fc binding was validated using functional experiments carried out with primary human NK cells from at least three healthy volunteers. 


\section{HLA-C Peptide Sequencing}

Human leukocyte antigen- $\mathrm{C}$ bound peptides were sequenced as described $(48,49)$. HLA-C was affinity purified from cell lysates of $1 \times 10^{10} 221-\mathrm{C}^{\star} 05: 01-\mathrm{His}_{10}$ using a $\mathrm{Ni}^{2+}$ column followed by W6/32 column. NHS:N-hydroxysuccinimide-activated Sepharose 4 fast flow (Pharmacia Biotech) was incubated with W6/32 $\mathrm{mAb}$ (5 $\mathrm{mg}$ protein/ml Sepharose) overnight at room temperature. The column was blocked with $100 \mathrm{mM}$ ethanolamine, $\mathrm{pH} 9.0$, overnight before extensive washing with PBS. Filtered lysates of $221-C^{\star} 05: 01$ cells were passed over a pre-column (IgG2a) followed by the W6/32 column. Columns were washed with 20 column volumes of lysis buffer, low salt buffer, high salt buffer, and no salt buffer. Lysis buffer was 20 mM Tris- $\mathrm{HCl}$ pH 8.0 with $150 \mathrm{mM} \mathrm{NaCl}$ with 1\% CHAPS, $1 \mathrm{mM}$ EDTA, $0.2 \%$ sodium azide, and protease inhibitors. Low salt buffer was $50 \mathrm{mM}$ Tris- $\mathrm{HCl}$ with $250 \mathrm{mM} \mathrm{NaCl}(\mathrm{pH} \mathrm{8.0)}$. High salt buffer was $50 \mathrm{mM}$ Tris- $\mathrm{HCl}$ with $1 \mathrm{mM} \mathrm{NaCl}(\mathrm{pH}$ 8.0). No salt buffer was $50 \mathrm{mM}$ Tris- $\mathrm{HCl}$ ( $\mathrm{pH} 8.0)$. HLA-C was eluted from the W6/32 column with four-column volumes of $0.2 \mathrm{M}$ acetic acid. Peptides were separated by ultrafiltration to remove HLA-C heavy chain and $\beta_{2} \mathrm{M}(3 \mathrm{kDa}$, Amicon Ultra-15; Millipore, USA). The filtrate was made up in $10 \%$ acetic acid and frozen. One milliliter was dried down in a speed vac and reconstituted at $1 \times 10^{7}$ cell equivalents $/ \mu$ in $0.1 \%$ acetic acid. Approximately $2 \times 10^{7}$ cell equivalents were made up to $4 \mu \mathrm{l}$ in $0.1 \%$ acetic acid and spiked with 100 fmol internal standards angiotensin and vasoactive peptide. Sample was loaded onto an irregular $\mathrm{C} 18(5-20 \mu \mathrm{M}$ diameter) capillary pre-column (360 $\mu \mathrm{M}$ outer diameter and $75 \mu \mathrm{M}$ inner diameter) and washed with $0.1 \%$ acetic acid before connecting the pre-column to a C18 analytical capillary column $(360 \mu \mathrm{M}$ outer diameter and $50 \mu \mathrm{M}$ inner diameter) equipped with an electrospray emitter tip. Peptides were gradient eluted by increasing organic solvent from $100 \%$ solvent A with $0 \%$ solvent B to $60 \%$ solvent B over 60 min (where solvent $\mathrm{A}$ is $0.1 \mathrm{M}$ acetic acid in $\mathrm{H}_{2} \mathrm{O}$ and solvent $\mathrm{B}$ is $70 \%$ acetonitrile and $0.1 \mathrm{M}$ acetic acid). Ions were electrosprayed into a high-resolution mass spectrometer on elution (Thermo Orbitrap XL, USA). The five most abundant precursor masses present in MS1 were selectively fragmented in a linear ion trap by collision activated dissociation followed by electron transfer dissociation. On completion, the open mass spectrometry search algorithm was used to search the human RefSeq NCBI Reference Sequence Database (http://www.ncbi.nlm.nih.gov/ refseq/). Peptides were manually validated.

\section{Peptide HLA-C Stabilization Assays}

Peptide stabilization of HLA-C was assessed by flow cytometry largely as described $(19,21,33)$. A total of $1.25 \times 10^{5}$ cells were incubated overnight at $26^{\circ} \mathrm{C}$ with $100 \mu \mathrm{M}$ of synthetic peptide, as indicated. The following day cells stained with PE-Cy5 HLA-A, B, C, mAb (G46-2.6, BD) at $4^{\circ} \mathrm{C}$. Peptides were synthesized by GL Biochem (Shanghai Ltd., Shanghai, China) and Peptide 2.0 (USA).

\section{KIR-Fc-Binding Assay}

Killer cell Ig-like receptors-Fc binding to cell lines and peptide-loaded cells was assessed by flow cytometry largely as described $(19,21)$. KIR2DL1*001-Fc, KIR2DL2*001-Fc and KIR2DL3*001-Fc (R\&D, 1844-KR, 3015-KR, 2014-KR) were conjugated to protein-A Alexa Flour 647 (Invitrogen) by overnight incubation at 9:1 (molar) at $4^{\circ} \mathrm{C}$, then diluted to $3.6 \mu \mathrm{g} /$ $\mathrm{ml}$ in PBS $+2 \%$ fetal calf serum (FCS). A total of $1.25 \times 10^{5}$ cells were placed in 96 flat well plates, resuspended in $25 \mu \mathrm{l}$ of KIR-Fc $\left(3.6 \mu \mathrm{g} / \mathrm{ml}\right.$ or as indicated) and incubated at $4^{\circ} \mathrm{C}$ for $1 \mathrm{~h}$. For peptide loaded cells, KIR-Fc binding was assessed after overnight incubation at $26^{\circ} \mathrm{C}$ with $100 \mu \mathrm{M}$ of synthetic peptide. KIR-Fc binding to 221 cells or protein A-Alexa Flour 647 alone were used to baseline values for KIR-Fc binding. Cells were washed with PBS and data acquired by flow cytometry.

\section{NK Cell Functional Assays}

Natural killer cell degranulation assays were carried out largely as described (19). For Figure 5 and Additional Files 3G,H and S7 in Supplementary Material, KIR A/A haplotype donor blood samples from healthy volunteers were recruited and collected under the Imperial College Healthcare NHS Trust Tissue Bank ethical approval (REC number 12/WA/0196). For Figure 6D and Additional File S8D in Supplementary Material, anonymous donors were recruited form the National Institutes of Health (NIH) blood bank. A total of $1 \times 10^{6}$ isolated PBMCs were incubated overnight at $37^{\circ} \mathrm{C}$ with $10 \mathrm{ng} / \mathrm{ml} \mathrm{IL-15}(\mathrm{R} \& \mathrm{D})$ and mixed the following day at 5:1 with 221 cell lines or peptide-loaded target cells in presence of $1 \mu \mathrm{l} \mathrm{BV} 421$ anti-CD107a mAb for $2 \mathrm{~h}$ at $37^{\circ} \mathrm{C}$ (H4A3, BD 562623). PBMCs were stained with mAbs to identify KIR SP NK cells. NK cells were identified as CD56+ (NCAM16.2, BD 562780) and CD3- (SK7, BD 557832). KIR2DL3-SP NK cells were KIR2DL3 ${ }^{+}$(180701, R\&D FAB2014F), KIR2DL1- (143211, R\&D FAB1844P), KIR3DL1- (DX9, Miltenyi Biotec 130-092474) and NKG2A- (Z199, Beckman Coulter PNB10246). For Figure 6D and Additional File S8 in Supplementary Material, donors with unknown KIR genotypes were screened for expression for KIR2DL1 and KIR2DS1 with combinations of mAbs (143211 \& EB6), as described (50). Flow cytometry panels were adjusted to allow isolation of KIR2DL1-SP NK cells if the donor carried KIR2DL1 and KIR2DS1. NK cell cytotoxicity assays were carried out with YTS NK cells mixed with 221 target cells at increasing effector target ratios, at $37^{\circ} \mathrm{C}$ for $2 \mathrm{~h}$. For experiments with $221-\mathrm{HLA}-\mathrm{C}^{+}$cell lines, the Europium release assay (Perkin Elmer, USA) was used as described (51). For assays using peptide loaded cells, propidium iodide incorporation assays were used as described (52).

\section{Cell Lines}

721.221 (221) cells and 221 cells expressing HLA-C ${ }^{\star} 04: 01$ were used (provided by J. Gumperz and P. Parham, Stanford University, USA). The RMA-S cell line expressing HLA-C ${ }^{\star} 08: 02$ is previously described (21). The 221 and RMA-S cell lines were cultured in RPMI or IMDM (Gibco) supplemented with 10\% FCS. YTS cell lines were previously described and cultured in IMDM with $12.5 \%$ FCS (51). HLA-C ${ }^{\star} 05: 01$ was expressed in 221 cells by retroviral transduction. Briefly, 293T cells stably expressing vesicular stomatitis virus (VSV) gag and pol genes were transiently transfected by calcium phosphate with $6 \mu \mathrm{g}$ each of VSVenvelope glycoprotein and HLA-C ${ }^{\star}$ 05:01 cDNAs. The medium 
was changed at $24 \mathrm{~h}$ and harvested at 48 and $72 \mathrm{~h}$ for infection. On consecutive days, filtered virus-containing supernatant was incubated with untransfected 221 cells and $8 \mu \mathrm{g} / \mathrm{ml}$ polybrene. The plate was centrifuged at $1,000 \times g, 32^{\circ} \mathrm{C}$ for $2 \mathrm{~h}$. Two days after infection, cells were selected in $1 \mu \mathrm{g} / \mathrm{ml}$ puromycin. ICP47 was expressed in 221 cell lines by electroporation as described $(53,54)$. Cell lines were cloned by limiting dilution after drug selection.

\section{Flow Cytometry}

Killer cell Ig-like receptors-Fc binding, HLA-I stabilization, degranulation, and cytotoxicity assays were acquired on a FACS ARIA II (BD, UK). Instrument identification: BD FACSAria II SORP configuration number 39305 (NIHR BRC FACS and Confocal Imaging Facility, Hammersmith Campus, Imperial College London, UK). Fluidics configuration: $85 \mu \mathrm{m}$ nozzle, $45 \mathrm{psi}$, frequency of $45 \mathrm{kHz}$, and a window extension of 2 . Optical configuration: $488 \mathrm{~nm}$ Laser Line: 780/50, 710/50, 670/14, 610/20, 575/25, 488/10; $633 \mathrm{~nm}$ Laser Line: 780/60, 710/50, 670/14; and 405 nm Laser Line: 610/20, 525/50, 450/40. Data were exported as FCS files and analyzed using FlowJo software (Treestar, version 10). Compensation for multicolor experiments was set using single mAb-stained beads, and Cytometer Setup and Tracking beads were run daily.

\section{Human Donors}

All studies were conducted according to the principles expressed in the Declaration of Helsinki. Healthy volunteers were recruited with informed consent with ethical approval either through the Imperial College Human Tissue Bank, London (REC number 12/ WA/0196) or from the NIH Department of Transfusion Medicine under an NIH Institutional Review Board-approved protocol with informed consent.

\section{Plasmids}

An HLA-C ${ }^{\star}$ 05:01 cDNA (55) was supplied by Pierre Coulie, as plasmid pcDNA3.1-HLA-C $C^{\star}$ 05:01 (de Duve Institute, Université Catholique de Louvain, UCL, Brussels, Belgium). Ten His residues followed by a stop codon were added to the $\mathrm{C}$-terminus of HLA-C ${ }^{\star}$ 05:01 by PCR of the HLA-C ${ }^{\star}$ 05:01 cDNA. HLA$\mathrm{C}^{\star}$ 05:01-10xHis was excised with BamHI and EcoRI and cloned into pBABE-puro- $\mathrm{CMV}^{+}$by blunt-end ligation via the SalI site. pzLRS-ICP47-IRES-GFP (56) was supplied by Emmanuel Wiertz (Center of Infectious Diseases and Department of Medical Microbiology, Leiden University Medical Center, Leiden, The Netherlands). HLA-C ${ }^{\star} 08: 02$ cDNA was generated by two single base changes in codons 77 and 80 of HLA- ${ }^{\star} 05: 01$ cDNA (Figure 1A) by Quickchange PCR of HLA-C ${ }^{\star} 05: 01$ using the primers.

Fwd: 5 -CAGACTGACCGAGTGAGCCTGCGGAACCT GCGCGGCTACTAC-3' and Rev: 5'-GTAGTAGCCGCGCAGG TTCCGCAGGCTCACTCGGTCAGTCTG-3'.

\section{Statistical Analysis}

All statistical analysis was carried out using GraphPad PRISM (version 5.0). Multiple groups were compared by Kruskal-Wallis test with Dunn's multiple comparisons test.

\section{AVAILABILITY OF DATA AND MATERIAL}

All data generated or analyzed during this study are included in this published article (and its Supplementary Material files).

\section{AUTHOR CONTRIBUTIONS}

MS designed the study, developed and performed experiments, interpreted data, and helped prepare the manuscript. SR, MP, and AK performed experiments. JS recruited healthy controls for the study. SM, JS, and DH carried out mass spectrometry analysis. $\mathrm{RB}, \mathrm{DA}$, and EL conceived and designed the study, interpreted the data, and prepared the manuscript. RB and EL. supervised the research and contributed equally to the study. All the authors discussed the results and commented on the manuscript.

\section{ACKNOWLEDGMENTS}

The authors thank M. Opanowicz, J. Manji, L. Black, J. Roberts, and the Imperial College London Hammersmith Campus NIHR BRC Flow Cytometry and Confocal Imaging Facility for assistance with flow cytometry. The authors also thank P. Coulie and E. Wiertz for plasmids and J. Gumperz and P. Parham for cell lines.

\section{FUNDING}

MS was supported by a 4-year Wellcome Trust-NIH PhD studentship (WT095472MA) and registered for a $\mathrm{PhD}$ at Imperial College London, UK. This work was supported by the following grants: NIHR BRC (P46708; RB), NIH (HHSN272200900046C; RB and DA), Wellcome Trust (087999/B/08/Z; RB and DA) and Welton Foundation (P14475; RB), and NIH (AI033993; DH). This work was supported in part by the Intramural Research Program of the NIH, National Institute of Allergy and Infectious Diseases (EL). The research was supported by the National Institute for Health Research (NIHR) Biomedical Research Centre based at Imperial College Healthcare NHS Trust and Imperial College London. The views expressed are those of the author(s) and not necessarily those of the NHS, the NIHR or the Department of Health. The funding bodies had no role in the design of the study, data collection, analysis, and interpretation of data, writing the manuscript or decision to publish.

\section{SUPPLEMENTARY MATERIAL}

The Supplementary Material for this article can be found online at http://journal.frontiersin.org/article/10.3389/fimmu. 2017.00193/full\#supplementary-material.

\begin{abstract}
ADDITIONAL FILE S1 | Sequence alignment of HLA-C*05:01 and HLA-C*08:02, generation of TAP-deficient cell line expressing HLA-C*05:01 and correlation of HLA-I stabilization. (A) Amino acid alignment of $\mathrm{HLA}-\mathrm{C}^{\star} 05: 01$ and $\mathrm{HLA}-\mathrm{C}^{\star} 08: 02$. Box indicates positions 77-80. (B) Expression of ICP47 (via IRES-GFP) and HLA-C in 221-C*05:01 cells transfected with pzLRS-ICP47-IRES-GFP. After drug selection, 221-C*05:01-ICP47 cell line was cloned by limiting dilution. (C) Correlation of HLA-I stabilization. HLA-C*05:01 against HLA-C*08:02 (Spearman).
\end{abstract}

ADDITIONAL FILE S2 | HLA-C*05:01 eluted peptide sequences and relative abundance. The relative abundance: $+=0-29 \mathrm{copies} / \mathrm{cell}$, 
$++=30-59$ copies/cell, $+++=60-100$ copies/cell, and $++++=>100$ copies/cell

\section{ADDITIONAL FILE S3 | HLA-C*05:01 is a functional ligand for KIR2DL1,} KIR2DL2 and KIR2DL3. (A) Expression of HLA-I and $\beta_{2}$ microglobulin on 221, 221-C*04:01 and 221-C*05:01 cells. (B,C) KIR2DL1-FC, KIR2DL2-FC, and KIR2DL3-Fc binding to 221, 221-C*04:01, and 221-C*05:01 cells as determined by flow cytometry. (C) Mean MFI and SEM are shown from three independent experiments. (D) Expression of KIR2DL1 and KIR2DL3 on YTS, YTS-2DL1, and YTS-2DL3 NK cells. (E) Specific lysis of 221, 221-C*04:01, and 221-C*05:01 cells by YTS, YTS-2DL1, and YTS-2DL3 NK cells at different effector-target ratios $(E: T)$. Mean and SEM of three independent experiments are shown. ${ }^{* *} \mathrm{p}<0.01$ and ${ }^{* \star *} \mathrm{p}<0.001$ by Student's t-test. (F) Flow cytometry gating strategy to identify KIR SP (KIR-SP) NK cells. CD56 ${ }^{\text {dim }}$ CD3- lymphocytes were identified from PBMCs. KIR2DL3-SP NK cells were identified as KIR3DL1- and NKG2A-', KIR2DL1- NK cells from A/A KIR haplotype donors. (G) Flow cytometry histograms showing degranulation (CD107a at the cell surface) of KIR3DL1 SP, KIR2DL1-SP, and KIR2DL3-SP NK cells in response to 221, 221-C*05:01, or no target cells. (H) Degranulation of KIR-SP NK cells in response to 221 and 221- $\mathrm{C}^{\star} 05: 01$ cells for $\mathrm{N}=5 \mathrm{~A} / \mathrm{A}$ KIR haplotype donors. Degranulation is shown relative to $221 .{ }^{* \star *} \mathrm{p}<0.001$ by Student's t-test.

ADDITIONAL FILE S4 | KIR2DL2 and KIR2DL3 binding to HLA-C*08:02 is more peptide selective than KIR2DL1 binding to HLA-C*05:01. Data from Figure 2B normalized to HLA-I (KIF-FC MFI/HLA-I MFI) for each peptide.

\section{ADDITIONAL FILE S5 | HLA-C*05:01 HIV Gag peptides modulate} canonical and cross-reactive binding of KIR2DL2 and KIR2DL3 to HLAC*05:01(C2). (A) HLA-C*05:01 HIV Gag 9mer peptide sequences.

(B) Expression of HLA-I on 221-C*05:01-ICP47 cells loaded with no peptide (NP), P2 and HIV Gag peptides 50-58, 60-68, 305-313, 310-318, and 427-435. Mean MFI and SEM of three independent experiments are shown. (C) Expression of HLA-I on RMA-S-C*08:02 cells loaded with NP, P2 and HIV Gag peptides 50-58, 60-68, 305-313, 310-318, and 427-435. Mean MFI and SEM of three independent experiments are shown. (D) KIR2DL1-Fc, KIR2DL2-Fc and KIR2DL3-Fc binding to 221-C*05:01-ICP47 cells loaded with NP, P2, or HIV Gag peptides, 50-58, 60-68, 305-313, 310-318, and 427-435. Mean MFI and

\section{REFERENCES}

1. Cerwenka A, Lanier LL. Natural killer cells, viruses and cancer. Nat Rev Immunol (2001) 1:41-9. doi:10.1038/35095564

2. Long EO, Sik Kim H, Liu D, Peterson ME, Rajagopalan S. Controlling natural killer cell responses: integration of signals for activation and inhibition. Annu Rev Immunol (2013) 31:227-58. doi:10.1146/annurev-immunol-020711075005

3. Parham P. MHC class I molecules and KIRs in human history, health and survival. Nat Rev Immunol (2005) 5:201-14. doi:10.1038/nri1570

4. Biassoni R, Falco M, Cambiaggi A, Costa P, Verdiani S, Pende D, et al. Amino acid substitutions can influence the natural killer (NK)-mediated recognition of HLA-C molecules. Role of serine-77 and lysine- 80 in the target cell protection from lysis mediated by "group 2" or "group 1" NK clones. J Exp Med (1995) 182:605-9. doi:10.1084/jem.182.2.605

5. Winter CC, Long EO. A single amino acid in the p58 killer cell inhibitory receptor controls the ability of natural killer cells to discriminate between the two groups of HLA-C allotypes. J Immunol (1997) 158:4026-8.

6. Boyton RJ, Altmann DM. Natural killer cells, killer immunoglobulin-like receptors and human leucocyte antigen class I in disease. Clin Exp Immunol (2007) 149:1-8. doi:10.1111/j.1365-2249.2007.03424.x

7. Boyton RJ, Altmann DM. Bronchiectasis: current concepts in pathogenesis, immunology, and microbiology. Annu Rev Pathol (2016) 11:523-54. doi:10.1146/annurev-pathol-012615-044344

8. Boyton RJ, Smith J, Ward R, Jones M, Ozerovitch L, Wilson R, et al. HLA-C and killer cell immunoglobulin-like receptor genes in idiopathic bronchiectasis. Am J Respir Crit Care Med (2006) 173:327-33. doi:10.1164/ rccm.200501-124OC

9. Khakoo SI, Thio CL, Martin MP, Brooks CR, Gao X, Astemborski $\mathrm{J}$, et al. HLA and NK cell inhibitory receptor genes in resolving
SEM of three independent experiments are shown. (E) KIR2DL1-Fc, KIR2DL2FC, and KIR2DL3-Fc binding to RMA-S-C*08:02 cells loaded with NP, P2, or HIV Gag peptides, 50-58, 60-68, 305-313, 310-318, and 427-435. Mean MFI and SEM of three independent experiments are shown.

\section{ADDITIONAL FILE S6 | Stabilization of HLA-I on TAP-deficient cells} by peptides and cross-reactive binding of KIR2DL2 to peptide-loaded HLA-C*05:01 and KIR2DL1 to peptide-loaded HLA-C*08:02. (A) Sequences of peptides P2, P10, P11 and peptides with amino acid substitutions at positions 7 and 8. (B) HLA-I expression on 221-C*05:01-ICP47 cells after overnight culture in the presence of HLA-C 05:01 peptides P2, P10, P11, and amino acidsubstituted peptides compared to cells with NP. Mean MFI and SEM of three independent experiments are shown. (C) HLA-I expression on RMA-S-C*08:02 cells after overnight culture in the presence of $\mathrm{HLA}-\mathrm{C}^{\star}$ 05:01 peptides P2, P10, P11, and amino acid-substituted peptides compared to cells with NP. Mean MFI and SEM of three independent experiments are shown. (D) KIR2DL2-Fc (left) and KIR2DL1-FC (right) binding to HLA-C*05:01 is correlated with binding to $\mathrm{HLA}-\mathrm{C}^{\star} 08: 02$ in the presence of the same peptides. All peptides with amino acid substitutions are shown.

\section{ADDITIONAL FILE S7 | Degranulation of KIR3DL1-SP NK cells in} response to peptide-loaded TAP-deficient HLA-C*05:01 cells. KIR3DL1-SP NK cell CD107a expression (\% positive) in response to 221-C*05:01-ICP47 cells loaded with NP, P2, P2-AA, P2-EE, P2-LA, P2-GG, P11, P11-7A, P10, P10-AA, and P10-7E. Individual donors are represented by different colors.

\section{ADDITIONAL FILE S8 | KIR-Fc binding and functional responses of KIR+} NK cells to $221-C^{\star} 08: 02$ and 221-C*08:02-ICP47 cells. (A) KIR2DL1-FC, KIR2DL2-FC, and KIR2DL3-Fc binding to 221, 221-C*08:02 and 221-C*15:01. (B) Specific lysis of 221 and $221-C^{*} 08: 02$ cells by YTS, YTS-2DL1, and YTS2DL3 NK cells. (C) KIR2DL1-Fc binding to 221-C*08:02-ICP47 cells loaded with NP or P10. (D) KIR3DL1-SP NK cell CD107a expression (\% positive) in response to 221-C*08:02-ICP47 cells loaded with NP, P2, P2-AA, P2-EE, P2-LA, P2-GG, P11, P11-7A, P10, P10-AA, and P10-7E. Individual donors are represented by different colors. (E) Overlay of cross-reactive KIR-SP NK cell responses and cross-reactive KIR-Fc binding to HLA-C*05:01 and HLA-C*08:02. hepatitis C virus infection. Science (2004) 305:872-4. doi:10.1126/science. 1097670

10. Hiby SE, Walker JJ, O'shaughnessy KM, Redman CW, Carrington M, Trowsdale J, et al. Combinations of maternal KIR and fetal HLA-C genes influence the risk of preeclampsia and reproductive success. J Exp Med (2004) 200:957-65. doi:10.1084/jem.20041214

11. Hiby SE, Apps R, Chazara O, Farrell LE, Magnus P, Trogstad L, et al. Maternal KIR in combination with paternal HLA-C2 regulate human birth weight. J Immunol (2014) 192:5069-73. doi:10.4049/jimmunol.1400577

12. Parham P, Moffett A. Variable NK cell receptors and their MHC class I ligands in immunity, reproduction and human evolution. Nat Rev Immunol (2013) 13:133-44. doi:10.1038/nri3370

13. Kulkarni S, Martin MP, Carrington M. The Yin and Yang of HLA and KIR in human disease. Semin Immunol (2008) 20:343-52. doi:10.1016/j. smim.2008.06.003

14. Khakoo SI, Carrington M. KIR and disease: a model system or system of models? Immunol Rev (2006) 214:186-201. doi:10.1111/j.1600-065X.2006. 00459.x

15. Rajagopalan S, Long EO. Understanding how combinations of HLA and KIR genes influence disease. J Exp Med (2005) 201:1025-9. doi:10.1084/ jem.20050499

16. Ruggeri L, Capanni M, Urbani E, Perruccio K, Shlomchik WD, Tosti A, et al. Effectiveness of donor natural killer cell alloreactivity in mismatched hematopoietic transplants. Science (2002) 295:2097-100. doi:10.1126/ science. 1068440

17. Ruggeri L, Capanni M, Casucci M, Volpi I, Tosti A, Perruccio K, et al. Role of natural killer cell alloreactivity in HLA-mismatched hematopoietic stem cell transplantation. Blood (1999) 94:333-9.

18. Cichocki F, Verneris MR, Cooley S, Bachanova V, Brunstein CG, Blazar $\mathrm{BR}$, et al. The past, present, and future of NK cells in hematopoietic cell 
transplantation and adoptive transfer. Curr Top Microbiol Immunol (2016) 395:225-43. doi:10.1007/82_2015_445

19. Fadda L, Borhis G, Ahmed P, Cheent K, Pageon SV, Cazaly A, et al. Peptide antagonism as a mechanism for NK cell activation. Proc Natl Acad Sci U S A (2010) 107:10160-5. doi:10.1073/pnas.0913745107

20. Zappacosta F, Borrego F, Brooks AG, Parker KC, Coligan JE. Peptides isolated from HLA-Cw*0304 confer different degrees of protection from natural killer cell-mediated lysis. Proc Natl Acad Sci U S A (1997) 94:6313-8. doi:10.1073/ pnas.94.12.6313

21. Rajagopalan S, Long EO. The direct binding of a p58 killer cell inhibitory receptor to human histocompatibility leukocyte antigen (HLA)-Cw4 exhibits peptide selectivity. JExp Med (1997) 185:1523-8. doi:10.1084/jem.185. 8.1523

22. Holzemer A, Thobakgale CF, Jimenez Cruz CA, Garcia-Beltran WF, Carlson JM, van Teijlingen NH, et al. Selection of an HLA-C ${ }^{\star} 03: 04-$ restricted HIV-1 p24 Gag sequence variant is associated with viral escape from KIR2DL3+ natural killer cells: data from an observational cohort in South Africa. PLoS Med (2015) 12:e1001900; discussion e1001900. doi:10.1371/journal.pmed. 1001900

23. Alter G, Heckerman D, Schneidewind A, Fadda L, Kadie CM, Carlson JM, et al. HIV-1 adaptation to NK-cell-mediated immune pressure. Nature (2011) 476:96-100. doi:10.1038/nature10237

24. Fan QR, Long EO, Wiley DC. Crystal structure of the human natural killer cell inhibitory receptor KIR2DL1-HLA-Cw4 complex. Nat Immunol (2001) 2:452-60.

25. Boyington JC, Motyka SA, Schuck P, Brooks AG, Sun PD. Crystal structure of an NK cell immunoglobulin-like receptor in complex with its class I MHC ligand. Nature (2000) 405:537-43. doi:10.1038/35014520

26. Graef T, Moesta AK, Norman PJ, Abi-Rached L, Vago L, Older Aguilar AM, et al. KIR2DS4 is a product of gene conversion with KIR3DL2 that introduced specificity for HLA-A ${ }^{\star} 11$ while diminishing avidity for HLA-C. J Exp Med (2009) 206:2557-72. doi:10.1084/jem.20091010

27. Moesta AK, Norman PJ, Yawata M, Yawata N, Gleimer M, Parham P. Synergistic polymorphism at two positions distal to the ligand-binding site makes KIR2DL2 a stronger receptor for HLA-C than KIR2DL3. J Immunol (2008) 180:3969-79. doi:10.4049/jimmunol.180.6.3969

28. Winter CC, Gumperz JE, Parham P, Long EO, Wagtmann N. Direct binding and functional transfer of NK cell inhibitory receptors reveal novel patterns of HLA-C allotype recognition. J Immunol (1998) 161:571-7.

29. Hilton HG, Vago L, Older Aguilar AM, Moesta AK, Graef T, Abi Rached L, et al. Mutation at positively selected positions in the binding site for HLA-C shows that KIR2DL1 is a more refined but less adaptable NK cell receptor than KIR2DL3. JImmunol (2012) 189:1418-30. doi:10.4049/jimmunol. 1100431

30. Rasmussen M, Harndahl M, Stryhn A, Boucherma R, Nielsen LL, Lemonnier FA, et al. Uncovering the peptide-binding specificities of HLA-C: a general strategy to determine the specificity of any MHC class I molecule. J Immunol (2014) 193:4790-802. doi:10.4049/jimmunol.1401689

31. York IA, Roop C, Andrews DW, Riddell SR, Graham FL, Johnson DC. A cytosolic herpes simplex virus protein inhibits antigen presentation to $\mathrm{CD}^{+}$T lymphocytes. Cell (1994) 77:525-35. doi:10.1016/0092-8674(94) 90215-1

32. Peruzzi M, Parker KC, Long EO, Malnati M. Peptide sequence requirements for the recognition of HLA-B $* 2705$ by specific natural killer cells. J Immunol (1996) 157:3350-6.

33. Sim MJ, Stowell J, Sergeant R, Altmann DM, Long EO, Boyton RJ. KIR2DL3 and KIR2DL1 show similar impact on licensing of human NK cells. Eur J Immunol (2016) 46:185-91. doi:10.1002/eji.201545757

34. Moesta AK, Parham P. Diverse functionality among human NK cell receptors for the C1 epitope of HLA-C: KIR2DS2, KIR2DL2, and KIR2DL3. Front Immunol (2102) 3:336. doi:10.3389/fimmu.2012.00336

35. Wagtmann N, Rajagopalan S, Winter CC, Peruzzi M, Long EO. Killer cell inhibitory receptors specific for HLA-C and HLA-B identified by direct binding and by functional transfer. Immunity (1995) 1995(3):801-9. doi:10.1016/1074-7613(95)90069-1

36. Xiong S, Sharkey AM, Kennedy PR, Gardner L, Farrell LE, Chazara $\mathrm{O}$, et al. Maternal uterine NK cell-activating receptor KIR2DS1 enhances placentation. JClin Invest (2013) 123:4264-72. doi:10.1172/ JCI68991
37. Hiby SE, Apps R, Sharkey AM, Farrell LE, Gardner L, Mulder A, et al. Maternal activating KIRs protect against human reproductive failure mediated by fetal HLA-C2. J Clin Invest (2010) 120:4102-10. doi:10.1172/JCI43998

38. Maenaka K, Juji T, Nakayama T, Wyer JR, Gao GF, Maenaka T, et al. Killer cell immunoglobulin receptors and $\mathrm{T}$ cell receptors bind peptide-major histocompatibility complex class I with distinct thermodynamic and kinetic properties. J Biol Chem (1999) 274:28329-34. doi:10.1074/jbc.274.40.28329

39. Vales-Gomez M, Reyburn HT, Mandelboim M, Strominger JL. Kinetics of interaction of HLA-C ligands with natural killer cell inhibitory receptors. Immunity (1998) 9:337-44. doi:10.1016/S1074-7613(00)80616-0

40. Hilton HG, Guethlein LA, Goyos A, Nemat-Gorgani N, Bushnell DA, Norman PJ, et al. Polymorphic HLA-C receptors balance the functional characteristics of KIR haplotypes. J Immunol (2015) 195:3160-70. doi:10.4049/ jimmunol.1501358

41. Frazier WR, Steiner N, Hou L, Dakshanamurthy S, Hurley CK. Allelic variation in KIR2DL3 generates a KIR2DL2-like receptor with increased binding to its HLA-C ligand. J Immunol (2013) 190:6198-208. doi:10.4049/ jimmunol.1300464

42. Béziat V, Hilton HG, Norman PJ, Traherne JA. Deciphering the killer-cell immunoglobulin-like receptor system at super-resolution for natural killer and T cell biology. Immunology (2017) 150:248-64. doi:10.1111/imm.12684

43. Lunemann S, Martrus G, Hölzemer A, Chapel A, Ziegler M, Körner C, et al. Sequence variations in HCV core-derived epitopes alter binding of KIR2DL3 to HLA-C ${ }^{*} 03: 04$ and modulate NK cell function. J Hepatol (2016) 65:252-8. doi:10.1016/j.jhep.2016.03.016

44. Tu M, Mahmoud AB, Makrigiannis AP. Licensed and unlicensed NK cells: differential roles in cancer and viral control. Front Immunol (2016) 7:166. doi:10.3389/fimmu.2016.00166

45. Mahmoud AB, Tu MM, Wight A, Zein HS, Rahim MM, Lee SH, et al. Influenza virus targets class I MHC-educated NK cells for immunoevasion. PLoS Pathog (2016) 12:e1005446. doi:10.1371/journal.ppat.1006021

46. Orr MT, Murphy WJ, Lanier LL. 'Unlicensed' natural killer cells dominate the response to cytomegalovirus infection. Nat Immunol (2010) 11:321-7. doi:10.1038/ni.1849

47. Landtwing V, Raykova A, Pezzino G, Béziat V, Marcenaro E, Graf C, et al. Cognate HLA absence in trans diminishes human NK cell education. J Clin Invest (2016) 126:3772-82. doi:10.1172/JCI86923

48. Cobbold M, De La Pena H, Norris A, Polefrone JM, Qian J, English AM, et al. MHC class I-associated phosphopeptides are the targets of memory-like immunity in leukemia. Sci Transl Med (2013) 5:203ra125. doi:10.1126/ scitranslmed.3006061

49. Udeshi ND, Compton PD, Shabanowitz J, Hunt DF, Rose KL. Methods for analyzing peptides and proteins on a chromatographic timescale by electrontransfer dissociation mass spectrometry. Nat Protoc (2008) 11:1709-17. doi:10.1038/nprot.2008.159

50. Fauriat C, Ivarsson MA, Ljunggren HG, Malmberg KJ, Michaelsson J. Education of human natural killer cells by activating killer cell immunoglobulin-like receptors. Blood (2010) 115:1166-74. doi:10.1182/blood-2009-09245746

51. Peterson ME, Long EO. Inhibitory receptor signaling via tyrosine phosphorylation of the adaptor Crk. Immunity (2008) 29:578-88. doi:10.1016/ j.immuni.2008.07.014

52. Thomas LM, Peterson ME, Long EO. Cutting edge: NK cell licensing modulates adhesion to target cells. J Immunol (2013) 191(8):3981-5. doi:10.4049/ jimmunol.1301159

53. Kumar S, Sarkar P, Sim MJ, Rajagopalan S, Vogel SS, Long EO. A single amino acid change in inhibitory killer cell Ig-like receptor results in constitutive receptor self-association and phosphorylation. J Immunol (2015) 194(2): 817-26. doi:10.4049/jimmunol.1401830

54. Gumperz J. Generation of HLA class I transfected target cell lines. Methods Mol Biol (2000) 121:49-60. doi:10.1385/1-59259-044-6:49

55. Baurain JF, Coulie PG. Correction of HLA-Cw*0501 and identification of HLA-Cw*0711. Tissue Antigens (1999) 53:510-2. doi:10.1034/j.1399-0039. 1999.530508.x

56. Oosten LE, Koppers-Lalic D, Blokland E, Mulder A, Ressing ME, Mutis T, et al. TAP-inhibiting proteins US6, ICP47 and UL49.5 differentially affect minor and major histocompatibility antigen-specific recognition by cytotoxic T lymphocytes. Int Immunol (2007) 19:1115-22. doi:10.1093/intimm/ dxm082 
Conflict of Interest Statement: The authors declare that the research was conducted in the absence of any commercial or financial relationships that could be construed as a potential conflict of interest.

Copyright (C) 2017 Sim, Malaker, Khan, Stowell, Shabanowitz, Peterson, Rajagopalan, Hunt, Altmann, Long and Boyton. This is an open-access article distributed under the terms of the Creative Commons Attribution License (CC BY). The use, distribution or reproduction in other forums is permitted, provided the original author(s) or licensor are credited and that the original publication in this journal is cited, in accordance with accepted academic practice. No use, distribution or reproduction is permitted which does not comply with these terms. 